\title{
Projected precipitation changes within the Great Lakes and Western Lake Erie Basin: a multi-model analysis of intensity and seasonality
}

\author{
Samantha J. Basile, ${ }^{a}$ Sara A. Rauscher ${ }^{\mathrm{b}}$ and Allison L. Steiner ${ }^{\mathrm{a} *}$ (1) \\ ${ }^{a}$ Department of Climate and Space Sciences and Engineering, University of Michigan, Ann Arbor, MI, USA \\ ${ }^{\mathrm{b}}$ Department of Geography, University of Delaware, Newark, DE, USA
}

\begin{abstract}
The Great Lakes region encompasses the largest freshwater lake network in the world and supports a diverse network of agriculture, transportation, and tourism. Recently, Lake Erie has experienced increased hypoxia events, which have been attributed to agricultural practices and changes in run-off. Here we examine the projected changes in extreme precipitation events to address concerns regarding regional agriculture, surface run-off, and subsequent water quality. Precipitation projections within the overall Great Lakes Basin and the Western Lake Erie Basin subregion are examined using climate model simulations of varying spatial resolutions to understand historical precipitation and projected future precipitation. We develop three model ensembles for the historical period (1980-1999) and the mid-century (2041-2060) that cover a range of spatial resolutions and future emissions scenarios, including: (1) 12 global model members from the fifth Climate Model Intercomparison Project (CMIP5) using Representative Concentration Pathway (RCP) 8.5, (2) ten regional climate model (RCM) members from the North American Regional Climate Change Assessment Program driven by CMIP3 global models using the A2 emissions scenario, and (3) two high resolution RCM simulations (RCM4) driven by CMIP5 global models using the RCP 8.5 scenario. For the historical period, all model ensembles overestimate winter and spring precipitation, and many of the models simulate a summer drying that is not observed. At mid-century, most of the models predict a $10-20 \%$ increase in precipitation depending on the time of year. Daily probability distribution functions from three model ensembles reveal spring seasonal increases in high precipitation event probabilities when compared to the historical period, suggesting an increase in the frequency of high intensity precipitation at mid-century. Overall, the presence of lakes or higher spatial resolution does not ensure improved representation of historical processes, and more complex interactions between large-scale dynamics, local feedbacks, and physical parameterizations drive the model spread.
\end{abstract}

KEY WORDS CMIP5; NARCCAP; regional climate; downscaling; extreme precipitation

Received 27 May 2016; Revised 10 April 2017; Accepted 11 April 2017

\section{Introduction}

The Laurentian Great Lakes have the largest freshwater lake surface area in the world and support a diverse network of agriculture, transportation, and tourism. Precipitation is a key element of the water cycle in the Great Lakes Basin (GLB; Gronewold et al., 2013; Gronewold and Stow, 2014), and the impacts of shifts in seasonal and daily precipitation have been documented across the region (Cherkauer and Sinha, 2010; Mishra and Cherkauer, 2011; Michalak et al., 2013). The release of greenhouse gases which feedback to a rise in global temperatures are associated with changes in precipitation, and are likely to induce more frequent heavy rain and flooding events (Karl et al., 2009; Melillo et al., 2014). The most recent National Climate Assessment identifies an increasing regional trend in total precipitation over the Midwestern United States since 1991 (Melillo et al., 2014). Further, for the Midwest

\footnotetext{
* Correspondence to: A. L. Steiner, Department of Climate and Space Sciences and Engineering, University of Michigan, 2455 Hayward Street, Ann Arbor, MI 48109-2143, USA. E-mail: alsteiner@umich.edu
}

and Northeast regions that encompass the Great Lakes, the amount of precipitation falling in very heavy events (the heaviest $1 \%$ of all daily events) has increased by 37 and $71 \%$, respectively over the same period (Melillo et al., 2014). Here, we investigate climate model simulations of precipitation seasonality and intensity in the GLB and how they are projected to change with future climate.

Climate model simulation of precipitation depends on a suite of atmospheric and terrain-induced physical processes. Both the models' spatial resolution and the inclusion of complex terrain and coastlines such as the Great Lakes have a large impact on simulated precipitation. Many of the global climate models in the third Climate Model Intercomparison Project (CMIP3; Meehl et al., 2007) and the fifth iteration (CMIP5; Taylor et al., 2012) have coarse spatial resolution such that they do not explicitly represent the Great Lakes. To increase the resolution in complex topographic regions such as the Great Lakes, two common downscaling techniques are employed: dynamical downscaling and statistical downscaling (Wilby et al., 1998). Dynamical downscaling is a technique that uses 
high-resolution regional models driven by global climate model boundary conditions. For example, the North American Regional Climate Change Assessment Program (NARCCAP) ensemble of regional climate model (RCM) simulations was driven with initial and lateral boundary conditions obtained from global climate model output from the CMIP3 archive (Mearns et al., 2013). In contrast, statistical downscaling relies on observed relationships between large-scale variables and local variables over a historical period, and applies these relationships to increase the spatial resolution of existing global climate model output. While less computationally intensive than dynamical downscaling, a major drawback of statistical downscaling is the stationarity assumption, which requires that the statistical relationships remain the same in the observed period and in the future.

Previous climate and climate impact studies centred around or in the Great Lakes region have used either ensembles of global climate model data or downscaled data to understand how future precipitation may change in the Great Lakes region. Using a suite of global models from CMIP3, a statistical downscaling study suggests that winter and spring precipitation may increase between 20 and $30 \%$ by the end of century (2070-2099) (Hayhoe et al., 2010). Patz et al. (2008) calculated a 10-40\% increase in the magnitude of extreme precipitation events in southern Wisconsin also based on CMIP3 model projections. A study using the NARCCAP ensemble to investigate changes across the agriculturally dominated Canadian prairie regions found up to a $15 \%$ increase in spring and summer precipitation as well as change in return periods for rain-dominated precipitation extremes (Khaliq et al., 2015). Vavrus and Behnke (2014) compared precipitation from global models with statistical and dynamically downscaled model output, and found a projected increase of annual precipitation $<10 \%$ with more seasonal precipitation in all seasons except summer, increases in the intensity of daily extreme precipitation events $(<30 \%$ increase in accumulation), and an even larger change in the return periods of extreme events (up to $-50 \%$ ).

Dynamically downscaled experiments have improved our understanding of the role of lake-atmosphere interactions in the present and under future climate conditions. Bryan et al. (2015) used dynamical downscaling with RegCM4 for the Great Lakes region to examine land-lake-atmosphere feedbacks in a high-resolution ensemble under present day conditions, and found that the simulation of lake temperature can introduce biases in simulated precipitation. Similar results were found when dynamically downscaling with the Weather Research and Forecast (WRF) model (Mallard et al., 2014). For future climate, Notaro et al. (2015) used dynamically downscaled simulations to show that cold-season precipitation is projected to increase due to reductions in lake ice cover, yet the frequency of the lake effect snowstorms is expected to decrease. Gula and Peltier (2012) found that a regional model (WRF) and its global driving model [the Community Climate System Model (CCSM)] produced different spatial patterns of projected precipitation over the Great Lakes region. The global model (CCSM) projected an increase $15-25 \%$ in annual precipitation by mid-century (2050-2060), whereas the dynamically downscaled WRF simulations showed a precipitation reduction in the southern Great Lakes region and an increase in the northern Great Lakes. This difference was attributed to atmosphere-lake feedbacks. d'Orgeville et al. (2014) also used WRF with different physics parameterizations, and found that precipitation extremes are expected to increase in the Great Lakes region. Together, these studies highlight that there may be added value in using high-resolution simulations that accurately resolve the lake and its physical properties, and that global models are not likely to capture these regional nuances.

In this study, we conduct a multi-scale regional analysis of Great Lakes precipitation to identify the role of climate model method and grid resolution on precipitation projections. We examine the GLB as a whole, which is noted to be difficult to simulate due to the treatment of the lakes (Mearns et al., 2013). We also evaluate the specific subregion of the Western Lake Erie Basin (WLEB). The WLEB is the subject of ongoing agricultural management studies connected to recurring harmful algal blooms in western Lake Erie, and these events are influenced by regional precipitation intensity (Michalak et al., 2013). Our analysis utilizes modelled output from one global model ensemble and two dynamically downscaled regional model ensembles. We compare output between a historical period (1980-1999) and high emissions scenario experiments for a mid-century period (2041-2060). We quantify changes in precipitation intensity and seasonality in the defined regions using daily and monthly rates to inform future climate change adaptation planning. Moreover, we highlight areas of confidence and uncertainty for the different ensembles to summarize the value of the multi-scale analysis.

\section{Methods}

The seasonal timing and daily magnitude of precipitation events are two metrics that can be used to quantify precipitation impacts. We use a suite of gridded observation products, RCM output, and global climate model output to assess present-day and future projections of precipitation in the Great Lakes region. We evaluate models during a historical time period, defined in this study as 1980-1999 based on overlapping data availability of observations and NARCCAP regional climate simulations (Mearns et al., 2013). For the future time period, we evaluate 2041-2060 based on NARCCAP time-slice experiment. We evaluate the seasonal cycle of precipitation [e.g. December-January-February (DJF), March-April-May (MAM), June-July-August (JJA), and September-October-November (SON)] for the historical period to understand model biases and also for the mid-century period to understand future changes in seasonality. To assess extreme precipitation, we use the maximum 1-day precipitation which is a common metric 
used to understand changes in intensity between the two time periods and model ensembles.

\subsection{Precipitation observations}

Modelled historical climate data is evaluated with the Climate Prediction Center's (CPC) Daily US Unified Precipitation data set between 1980 and 1999. The CPC Unified Precipitation data set uses distance weighting and optimal interpolation methods to resolve observations from over 30000 global observation stations to a $0.25^{\circ} \times 0.25^{\circ}$ gridded product (Chen et al., 2008). The 20-year historical time period was selected based on the revised definition of climatological time period by the World Meteorological Organization from a 30-year average to a 20-year average (Arguez and Vose, 2011) and the intersection with RCM simulations.

\subsection{Global climate model data}

Twelve atmosphere-ocean (AO) models of the CMIP5 (Taylor et al., 2012) comprise the global climate model ensemble (Table 1), with model data accessed through the Earth System Grid Federation's PCMDI, DKRZ, and NCAR nodes. For the future, we selected the Representative Concentration Pathway 8.5 (RCP 8.5) experiment, as present-day emissions are currently following this emissions projection (Peters et al., 2013). Only CMIP5 AO models with daily temporal output for the present-day and RCP 8.5 experiments were selected. The AO configuration is defined to include interactive atmosphere, land surface, ocean, and sea ice models as well as aerosol components, and captures water cycle feedbacks with the atmosphere (Flato et al., 2013).

\subsection{Regional climate model data}

RCMs, i.e. dynamical downscaling, have the potential advantage of preserving physical and dynamical relationships between variables, thus reducing the issue of stationarity associated with statistical downscaling (Gutierrez et al., 2013). These regional, higher resolution simulations require global climate model data or reanalysis data for lateral boundary conditions. For our analysis, we use ten regional NARCCAP simulations that provided daily precipitation for the present-day and future time periods at $50 \mathrm{~km}$ resolution for the $\mathrm{A} 2$ emissions scenario (Table 1). NARCCAP output was accessed through the Earth System Grid Federation PCMDI and NCAR nodes as 3-h precipitation fluxes, which were converted to daily precipitation rates $\left(\mathrm{mm} \mathrm{day}^{-1}\right)$. The full NARCCAP ensemble includes twelve simulations, but two of the simulations (WRFG-CCSM and HRM3-GFDL) use different treatment of the lakes in present day and future conditions, making the comparison of present day and future precipitation not possible given our focus region. In addition to the NARCCAP RCM ensemble, we also evaluate two RCM simulations at $25 \mathrm{~km}$ resolution (RCM-HiRes) with the RegCM4 (Giorgi et al., 2012), which uses two different CMIP5 GCM RCP 8.5 simulations as boundary conditions (Bryan et al., 2015) (Table 1).

\subsection{Spatial and temporal averaging}

The gridded observations, global ensembles, and regional ensembles were analysed for the GLB $\left(40^{\circ}-50^{\circ} \mathrm{N}\right.$, $\left.75^{\circ}-95^{\circ} \mathrm{W}\right)$, and the WLEB $\left(40^{\circ}-43^{\circ} \mathrm{N}, 82^{\circ}-85.5^{\circ} \mathrm{W}\right)$ (Figure 1). Each simulation was spatially averaged over the GLB and WLEB regions, with the number of grid cells within each region for each simulation detailed in Table 1 to highlight the range of resolution within the global and regional models.

Daily precipitation data were downloaded for the global model simulations, and 3-h precipitation data from the NARCCAP and RCM-HiRes were downloaded and aggregated to a daily basis for present-day (1980-1999) and future (2041-2060) precipitation intensity. We note that two NARCCAP ensemble members (CRCM-CCSM and MM5I-CCSM) did not simulate the complete year for 1999 and for these two members we use the present-day period of 1980-1998. For seasonal climatology, daily data were averaged to monthly for both the historical and future periods. Differences in precipitation rates between the present-day and future time periods were calculated from the monthly climatologies. For intensity, daily precipitation rate probabilities were sorted into 15 bins ranging from 0 to $90 \mathrm{~mm} \mathrm{day}^{-1}$. To account for the spatial variability within the GLB and WLEB averaging regions, maximum precipitation rates within each region were also evaluated using 20 bins ranging from 0 to $500 \mathrm{~mm} \mathrm{day}^{-1}$. For the WLEB, seasonal and daily spring biases were calculated for the historical period to inform run-off sensitivity modeling for the Maumee watershed located in northwestern Ohio. Over the historical period, precipitation events $>24 \mathrm{~mm} \mathrm{day}^{-1}$ (99th percentile) were considered 'extreme' for the Maumee watershed based on comparisons with daily gauge precipitation data between 1981 and 1999.

\section{Evaluation of precipitation seasonality and intensity}

\subsection{Precipitation seasonality}

\subsubsection{Observed historical precipitation (1980-1999)}

Observed seasonal precipitation for the GLB and the WLEB subregions show a clear unimodal pattern with a summer maximum (Figures 2(a) and 3(a), respectively). For the period 1980-1999, observed annual precipitation over the GLB is $832.6 \mathrm{~mm}$ with an annual minimum during late winter $\left(30.6 \mathrm{~mm} \mathrm{month}^{-1}\right.$ in February) and maximum during summer $\left(99.0 \mathrm{~mm} \mathrm{month}^{-1}\right.$ in June and $99.4 \mathrm{~mm} \mathrm{month}^{-1}$ in July) (Figure 2(a)). The seasonal cycle is similar in the WLEB region, with peak precipitation (97.1 and $97.8 \mathrm{~mm} \mathrm{month}^{-1}$ in June and July, respectively) and the mean minimum precipitation is higher $\left(46.7 \mathrm{~mm} \mathrm{month}^{-1}\right.$ in February; Figure 3(a)). Over the WLEB, total annual precipitation of $908.2 \mathrm{~mm}$ is slightly higher than the GLB region average. For the GLB, the summer season (JJA) includes the largest fraction (over one-third) of the averaged annual precipitation 
Table 1. Global and regional model ensemble details.

\begin{tabular}{|c|c|c|c|c|c|c|}
\hline \multirow{2}{*}{$\begin{array}{l}\text { Model type and emission scenario } \\
\text { Global, } R C P 8.5\end{array}$} & \multirow{2}{*}{$\begin{array}{l}\text { Atmospheric horizontal } \\
\text { resolution }\end{array}$} & \multicolumn{2}{|c|}{$\begin{array}{l}\text { Grid points }(\text { latitude } \times \\
\text { longitude }=\text { total })\end{array}$} & \multirow[t]{2}{*}{$\begin{array}{l}\text { Lake } \\
\text { mask }\end{array}$} & \multirow[t]{2}{*}{$\begin{array}{c}\text { Lake } \\
\text { temperature }\end{array}$} & \multirow[t]{2}{*}{$\begin{array}{r}\text { Lake } \\
\text { ice }^{\mathrm{a}}\end{array}$} \\
\hline & & WLEB & GLB & & & \\
\hline ACCESS1.0 & $1.25 \times 1.875$ & $3 \times 2=6$ & $9 \times 11=99$ & No & & \\
\hline ACCESS 1.3 & $1.25 \times 1.875$ & $3 \times 2=6$ & $9 \times 11=99$ & No & & \\
\hline CCSM4 & $0.9 \times 1.25$ & $4 \times 3=12$ & $11 \times 17=187$ & No & & \\
\hline CESM1-CAM5 & $0.9 \times 1.25$ & $4 \times 3=12$ & $11 \times 17=187$ & No & & \\
\hline CMCC-CM & $0.75 \times 0.75$ & $4 \times 5=20$ & $14 \times 27=378$ & Yes & $1 \mathrm{D}^{\mathrm{b}}$ & Yes \\
\hline CMCC-CMS & $1.875 \times 1.875$ & $2 \times 2=4$ & $6 \times 11=66$ & Yes & 1D & Yes \\
\hline CSIRO-Mk3.6.0 & $1.875 \times 1.875$ & $2 \times 2=4$ & $6 \times 11=66$ & No & & \\
\hline EC-EARTH & $1.125 \times 1.125$ & $2 \times 4=8$ & $9 \times 18=162$ & Yes & Interp $^{c}$ & No \\
\hline FGOALS-g2 & $2.8125 \times 2.8125$ & $1 \times 1=1$ & $4 \times 7=28$ & No & & \\
\hline HadGEM2-AO & $1.25 \times 1.875$ & $3 \times 2=6$ & $9 \times 11=99$ & No & & \\
\hline MIROC5 & $1.4 \times 1.4$ & $2 \times 2=4$ & $7 \times 14=98$ & No & & \\
\hline MRI-CGCM3 & $1.125 \times 1.125$ & $2 \times 4=8$ & $9 \times 18=162$ & No & & \\
\hline \multicolumn{7}{|c|}{ Regional, SRES A2 (RCM-driving GCM) } \\
\hline CRCM-CGCM3 & $50 \times 50$ & $9 \times 8=72$ & $30 \times 38=1140$ & Yes & $1 \mathrm{D}$ & Yes \\
\hline CRCM-CCSM & $50 \times 50$ & $9 \times 8=72$ & $30 \times 38=1140$ & Yes & 1D & Yes \\
\hline ECP2-GFDL & $50 \times 50$ & $9 \times 8=72$ & $31 \times 39=1209$ & Yes & Interp & No \\
\hline EPC2-HadCM3 & $50 \times 50$ & $9 \times 8=72$ & $31 \times 39=1209$ & Yes & Interp & No \\
\hline HRM3-HadCM3 & $50 \times 50$ & $8 \times 7=56$ & $28 \times 35=980$ & Yes & Interp & No \\
\hline MM5I-CCSM & $50 \times 50$ & $8 \times 6=48$ & $26 \times 33=858$ & Yes & Interp & No \\
\hline MM5I-HadCM3 & $50 \times 50$ & $8 \times 6=48$ & $26 \times 33=858$ & Yes & Interp & No \\
\hline RCM3-CGCM3 & $50 \times 50$ & $7 \times 7=49$ & $27 \times 34=918$ & Yes & Interp & No \\
\hline RCM3-GFDL & $50 \times 50$ & $7 \times 7=49$ & $27 \times 34=918$ & Yes & Interp & No \\
\hline WRFG-CGCM3 & $50 \times 50$ & $8 \times 6=48$ & $26 \times 33=858$ & Yes & Interp & Yes \\
\hline Regional, RCP 8.5 & (latitude × longitude, $\mathrm{km}$ ) & & & & & \\
\hline RCM4-HadGEM & $25 \times 25$ & $15 \times 14=210$ & $53 \times 68=3604$ & Yes & Interp & No \\
\hline RCM4-GFDL & $25 \times 25$ & $15 \times 14=210$ & $53 \times 68=3604$ & Yes & Interp & No \\
\hline
\end{tabular}

${ }^{\text {a }}$ Lake ice present in Great Lakes region.

b1D lake model for inland water points (Goyette et al., 2000).

${ }^{\mathrm{c}}$ Lake surface temperature interpolated from nearest lake point (if in parent GCM) or from the nearest sea surface temperature (e.g. from coastal regions).

(294.6 mm), with just less than one-fourth annual precipitation occurring in spring (198.7 mm; MAM). Summer also contains the highest fraction of WLEB precipitation $(284.8 \mathrm{~mm})$, however spring contains over one-fourth of its total precipitation $(236.9 \mathrm{~mm})$ (Table 2$)$.

\subsubsection{Modelled historical precipitation (1980-1999)}

We compare simulated annual and seasonal precipitation from the global and regional ensembles with CPC observations averaged over 1980-1999 (Figures 2 and 3; Table 2). For the GLB over the historical period, 11 of the 12 CMIP5 members and eight of the ten NARCCAP members simulate more annual precipitation than the observed historical value, while both RCM-HiRes members have a negative or dry bias. The GLB averaging region has wet biases in both spring and winter in all 12 CMIP5 models and all ten NARCCAP models (Figures 2(a) and (b)). In both RCM-HiRes members, the seasonality of the modelled precipitation is relatively flat as noted by Bryan et al. (2015), with a positive winter bias and a negative summer bias. All of the models in the region exhibit a positive winter bias, while the summer bias in these simulations may be due to a weak parameterization of convective precipitation. All ensemble members show a wet bias in DJF precipitation ranging from $19.7 \mathrm{~mm}(17.3 \%)$ to $108.3 \mathrm{~mm}(95.2 \%)$ (Figures 2(a)-(c)), although this may be in part attributed to the low observed values in the region influenced by gauge error for solid phase precipitation (Legates and Willmott, 1990). For example, gauge corrections based on the Legates and Willmott data can increase winter precipitation in the Great Lakes region by up to $0.5 \mathrm{~mm}$ day $^{-1}$. The CMIP5 ensemble mean overestimates MAM precipitation by $61.0 \mathrm{~mm}(30.7 \%)$, with individual wet model biases ranging between $2.3 \mathrm{~mm}$ $(1.2 \%)$ and $112.2 \mathrm{~mm}(56.5 \%)$. Similar to the global models, the NARCCAP ensemble mean shows a positive bias in MAM of $50.4 \mathrm{~mm}(25.4 \%)$ but with a narrower range in the model bias $(18.3-96.0 \mathrm{~mm})$. All NARCCAP models show a late spring/early summer (MJJ) peak that is stronger than observed (Figure 2(b)), and indicates that this ensemble shifts precipitation earlier in the season than observed and produces too much precipitation. In JJA, the inter-ensemble model spread grows, with 14 of the 24 total models exhibiting a summer dry bias and the rest exhibiting a wet bias (Figures 2(a)-(c)). As the summer progresses into fall, the intermodel CMIP5 spread narrows and individual model biases are reduced. In late summer/early fall (ASO), the NARCCAP ensemble reduces precipitation closer to observed, but then precipitation increases again in the winter, a feature not evident in the observations (Figure 2(b)). For the RCM-HiRes simulations, there is very little amplitude in the seasonal 


\section{GLB and WLEB Boundaries}

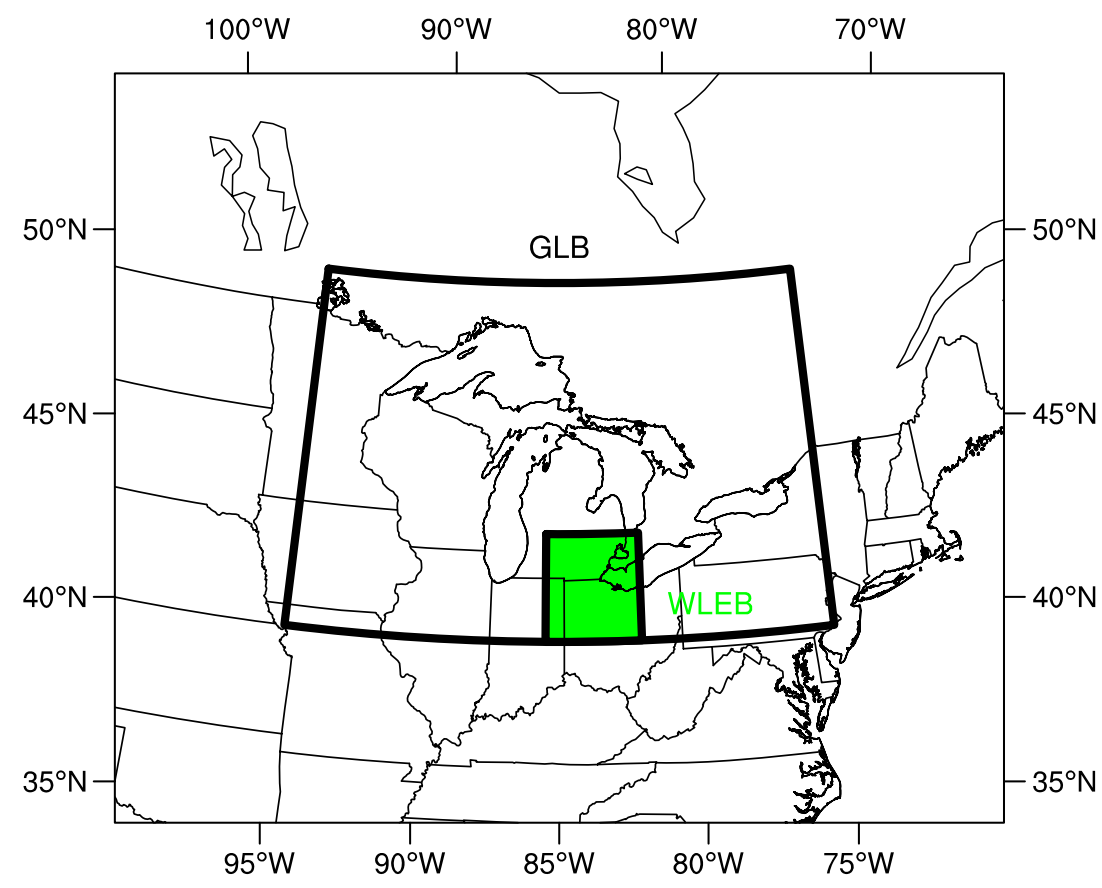

Figure 1. Boundaries representing the GLB and WLEB. The GLB includes the US Great Lakes states (U.S.) and Canada, and the WLEB includes the geographic extent of the watersheds that drain into the western basin of Lake Erie, including southeastern Michigan, northwestern Ohio, and northeastern Indiana. [Colour figure can be viewed at wileyonlinelibrary.com].

cycle, as discussed in Bryan et al. (2015). This leads to a comparatively small spring dry (negative) bias of $5.8 \mathrm{~mm}$ $(-2.9 \%)$ in the ensemble mean, although this is largely due to the flat seasonal cycle relative to the increase in winter to spring precipitation (Figure 2(c)).

For the WLEB region, most models also have a wet annual bias with the exception of one CMIP5 model (CSIRO), one NARCCAP model (CRCM-CCSM), and the RCM-HiRes simulations (Table 2; Figures 3(a)-(c)). The seasonal bias is strongest in MAM for all model ensemble means, with a positive bias of $69.9 \mathrm{~mm}$ (29.5\%) for CMIP5, a positive $60.1 \mathrm{~mm}(25.4 \%)$ bias for NARCCAP, and dry bias of $27.8 \mathrm{~mm}(-11.7 \%)$ for RCM-HiRes. The bias of individual CMIP5 members is similar to the larger region, falling between $4.7 \mathrm{~mm}(2.0 \%)$ and $122.9 \mathrm{~mm}$ $(51.9 \%)$, likely due to the differing model processes and wide range of spatial resolution in this ensemble. Similar to the GLB, the NARCCAP ensemble produces MAM precipitation that ranges close to the CMIP5 models, from $12.1 \mathrm{~mm}(5.1 \%)$ and $112.4 \mathrm{~mm}(47.4 \%)$ for individual model members (Figure 3(c)). Unlike the other ensembles, the RCM-HiRes shows a dry bias over land in the region (Bryan et al., 2015) with individual members showing a dry bias of $18.3 \mathrm{~mm}(-7.7 \%)$ and $37.2 \mathrm{~mm}(-15.7 \%$; Figure 3(e)).

\subsubsection{Modelled future precipitation (2041-2060)}

With knowledge of the biases in the historical simulations, we examine the relative percent change in seasonal precipitation for mid-century (2041-2060) for the GLB and the WLEB, respectively (Figures 2(d)-(f) and 3(d)-(f), respectively). For the GLB, the annual relative change in precipitation is typically positive and does not differ much between ensembles (CMIP5: -0.7 to $16.1 \%$, NARCCAP: 4.7-10.6\%, RCM-HiRes: 6.7-14.3\%; Figures 2(d)-(f)). The projected increase in annual precipitation is similar for the WLEB region, however the increase is slightly higher in the global and regional ensembles (CMIP5: -5.4 to $17.8 \%$, NARCCAP: $0.0-13.9 \%$, RCM-HiRes: $0.8-12.9 \%$; Figures 3(d)-(f)).

During spring and winter, precipitation is generally projected to increase across all ensemble members within both regions (Figures 2 and 3). Ensemble mean changes in MAM precipitation are small $(7.0-14.7 \%)$ for the GLB, with individual models ranging between 1.4 and $30.0 \%$ for the CMIP5 ensemble, -1.6 to $12.7 \%$ for the NARCCAP ensemble, and 12.5-17.0\% for the Hi-Res ensemble. For the WLEB, the spring ensemble mean changes have a smaller range $(8.4-12.8 \%)$ with more member variability (CMIP5: -3.6 to $33.6 \%$, NARCCAP: $1.5-19.2 \%$, Hi-Res: $9.8-15.8 \%$ ). The magnitude of winter precipitation change for the CMIP5 ensemble mean is similar for both regions (GLB: $17.4 \%$; WLEB: $17.9 \%$ ). The NARCCAP and RCM-HiRes ensemble means, present a lower increase than CMIP5 for the GLB (11.1 and 13.6\%, respectively). The regional models' magnitude of increase is slightly higher for the WLEB (11.5, 14.0\%; Figures 3(d) and (f)).

The greatest spread in the simulated future precipitation occurs in JJA, with some models showing decreases in future summer precipitation and some showing relative increases compared to the historical period (Figures 2 and 


\section{GLB seasonal precipitation and mid-century change}
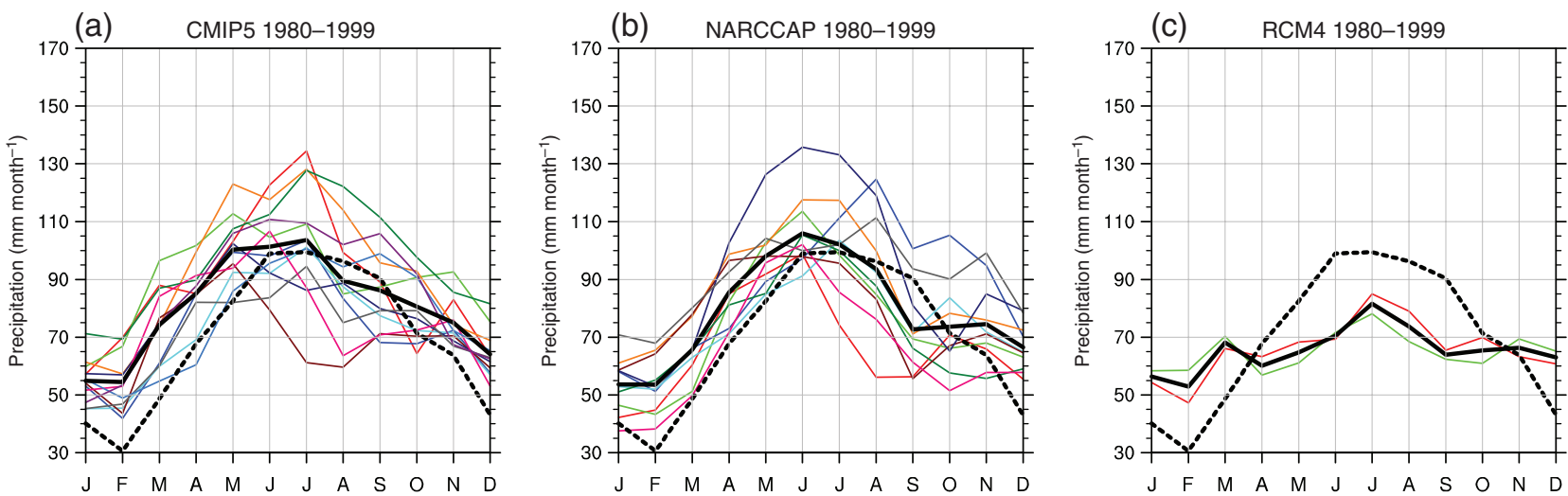

(d) CMIP5 change, 2041-2060

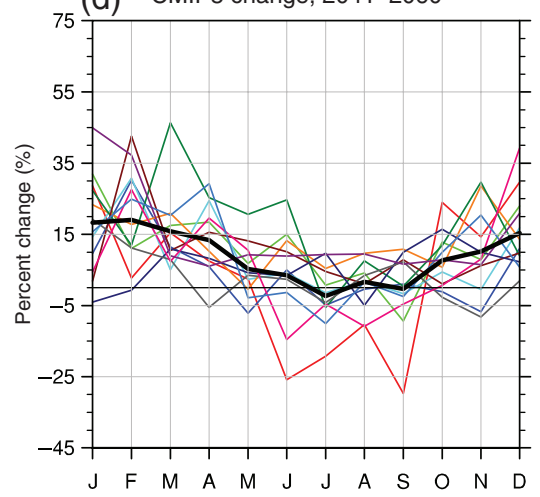

(e) NARCCAP change, 2041-2060

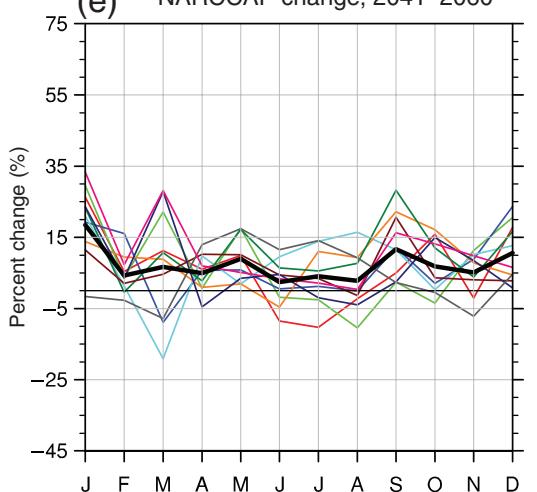

(f) RCM4 change, 2041-2060
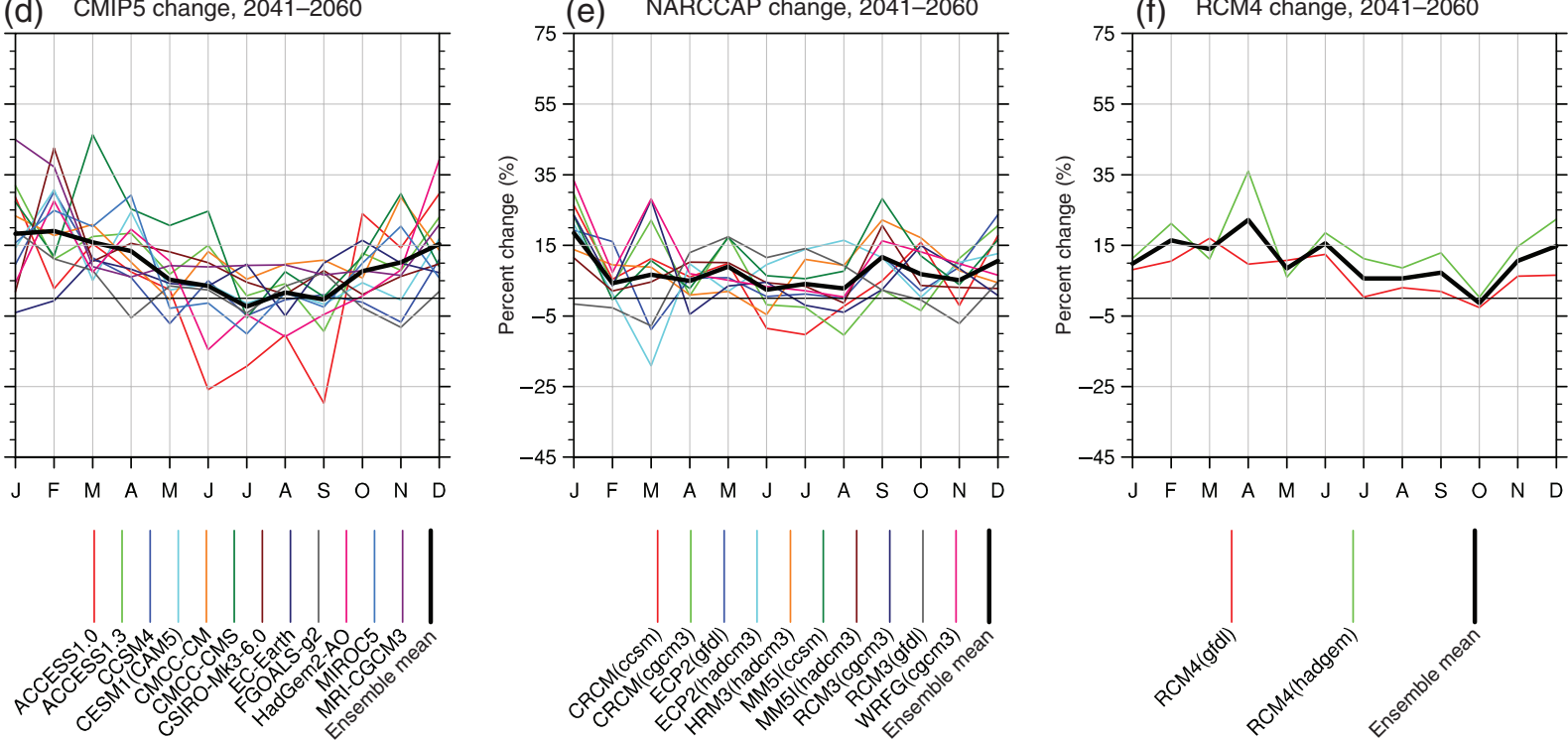

Figure 2. Monthly averages for the historical period (1980-1999) spatially averaged over the GLB for (a) the CMIP5 ensemble, (b) the NARCCAP ensemble, and (c) the RCM-HiRes ensemble. Individual model members in coloured lines, the multi-model average in solid black lines, and the CPC observed precipitation in black dotted lines. Monthly average changes projected for mid-century (2041-2060) normalized to a percent change from the historical period for (d) the CMIP5 ensemble, (e) the NARCCAP ensemble, and (c) the RCM-HiRes ensemble.

3). Although the ensemble mean changes show increases ranging from 0.9 to $8.8 \%$ in the GLB, in the WLEB, this range is -1.4 to $+1.6 \%$. For both the GLB and WLEB, 8 out of the 12 CMIP5 models show an increase in JJA precipitation (GLB: $0.2-9.3 \%$, WLEB: $1.3-14.1 \%$ ), while four show relative decreases (GLB: $0.2-19.0 \%$ decrease, WLEB: $1.0-20 \%$ decrease) (Figures 2(d) and 3(d)). For the regional NARCCAP ensemble, there is more variability between members although there is a similar spread in JJA between regions, with seven models predicting an increase in GLB precipitation and four models predicting an increase for the WLEB (GLB: 0.5-13.4\%, WLEB: $2.5-16.4 \%$, Figures 2 and $3(\mathrm{~d}))$. The range of predicted decrease is also similar from three models in the GLB and six models for the WLEB (GLB: 0.3-7.6 decrease, WLEB: $3.5-12.7 \%$ decrease, Figures 2 and 3(d)). The RCM-HiRes simulations are also split on the change in JJA precipitation for the WLEB (-8.4 decrease and 9.7\% increase), leading to a near zero change in precipitation in the ensemble mean whereas they both indicate an increase for the GLB (4.9 and 12.8\%; Figures 2 and 3(f)).

Overall, the response of seasonal precipitation at the mid-century time period is similar across both regions with most ensemble members, with ensemble means indicating an increase between 8.5 and $12.6 \%$ in the spring and 11.5 and $18 \%$ in the winter for the WLEB (Figures 2 and 3). The overall response of precipitation to the future climate scenarios is more variable during the summer and early fall, depending on the ensemble and member. However, we note that this increase is slightly smaller than the model bias in these seasons. This result is consistent with Hayhoe et al. (2010), who used two statistical downscaling techniques for precipitation in the Chicago and Great Lakes area and found that that winter and spring precipitation may increase up to $20 \%$ before end of century (2070-2099) under the similar A2 (or moderate) emissions scenario. Possible explanations for these changes are explored in Section 4. 
WLEB seasonal precipitation and mid-century change
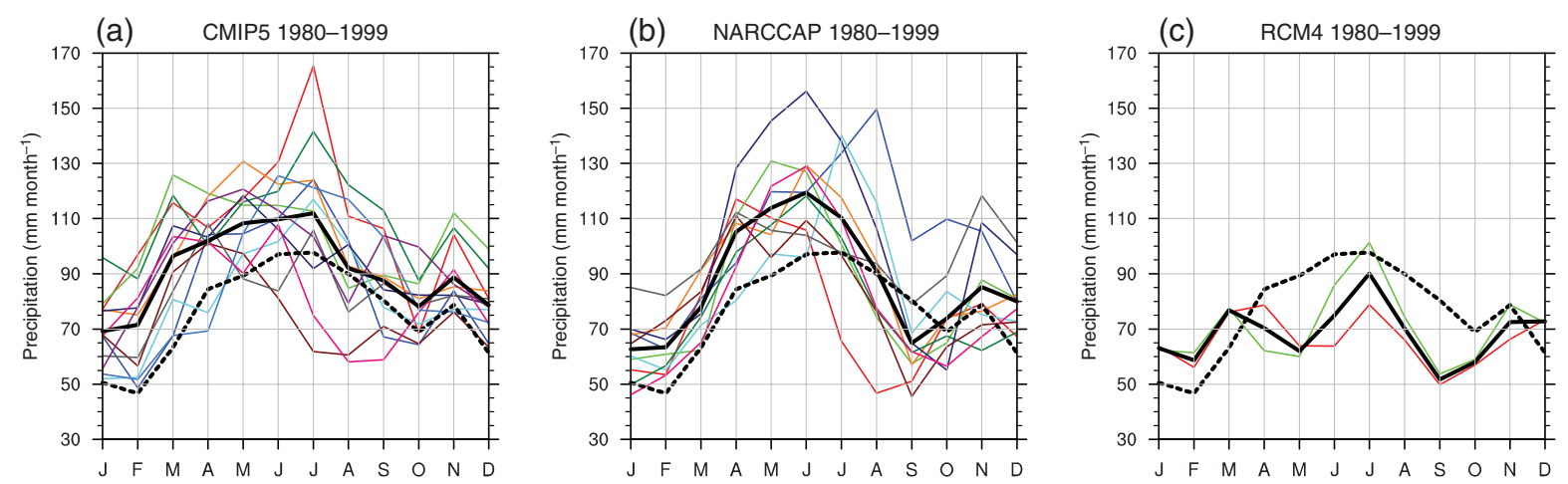

(d) CMIP5 change, 2041-2060
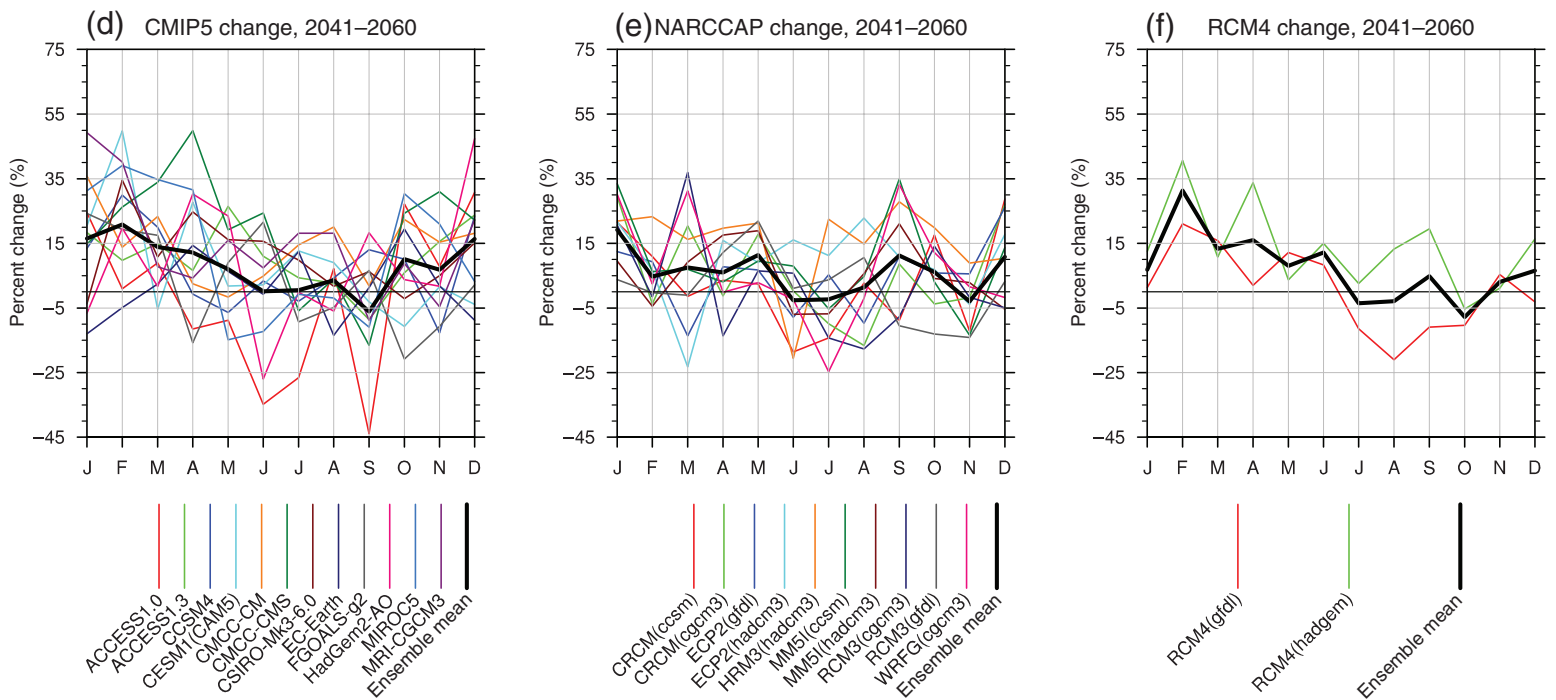

Figure 3. As for Figure 2, but for the WLEB.

\subsection{Precipitation intensity}

\subsubsection{Observed historical period precipitation intensity (1980-1999)}

We examine daily precipitation rates (or precipitation intensity) over the historical period with probability density functions, dividing daily precipitation into 15 equally spaced bins spanning $0-90 \mathrm{~mm} \mathrm{day}^{-1}$. We define three categories of events: small $\left(0-5 \mathrm{~mm} \mathrm{day}^{-1}\right)$, moderate $\left(6-23 \mathrm{~mm} \mathrm{day}^{-1}\right)$, and extreme events $\left(\geq 24 \mathrm{~mm}\right.$ day $\left.^{-1}\right)$. Simulated precipitation intensity is compared with daily CPC gridded observations, although we note that using a gridded product for intensity may smooth out individual stations that may experience higher, localized rainfall. However, this product provides continuous coverage of historical data for evaluation and a daily precipitation value that is spatially consistent with a model grid cell.

In the GLB region (Figures 4(a)-(d)), all ensemble members generally capture the observed intensities in all seasons except for DJF, where the models overestimate daily precipitation. For DJF, this suggests that the seasonal wet bias (Section 3.1.2.) is due to both more precipitation during the moderate events in most of the models (e.g. $6-23 \mathrm{mmday}^{-1}$ ) as well as the simulation of higher intensity events by some model members $\left(\geq 24 \mathrm{~mm} \mathrm{day}^{-1}\right)$ (Figure 4(d)). Other seasons, such as MAM, show that the models capture the frequency of moderate events $\left(6-23 \mathrm{~mm} \mathrm{day}^{-1}\right)$ but some model members simulate additional high intensity events $\left(\geq 24 \mathrm{~mm} \mathrm{day}^{-1}\right)$ (Figure 4(a)). The same pattern is evident in JJA (Figure 4(b)) and SON (Figure 4(c)). When comparing the model type in both MAM and DJF, the global models produce more intense events than the regional models (Figures 4(a)-(d)). For the RCM-HiRes ensemble, the spatially averaged precipitation shows lower mean probability values, consistent with the previously described summer season dry bias (Figure 4(b)).

For the WLEB subregion, simulated intensities are higher (up to $90 \mathrm{~mm} \mathrm{day}^{-1}$ ) than the GLB because of spatial averaging techniques (e.g. the WLEB subregion is $3^{\circ} \times 3.5^{\circ}$ and the GLB is $10^{\circ} \times 20^{\circ}$ ). With fewer grid cells, more of the individual grid intensities are captured with a smaller averaging region, increasing the regionally averaged intensity (Figures 5(a)-(d)). All model ensembles generally capture the JJA and SON moderate range intensities (e.g. 6-23 $\mathrm{mm} \mathrm{day}^{-1}$ ) but again have individual members that simulate higher intensity events that reach up to $83 \mathrm{~mm} \mathrm{day}^{-1}$ (Figures 5(b) and (c)). For MAM and DJF, the models overestimate the observed precipitation in the 
Table 2. WLEB annual precipitation ( $\mathrm{mm}$ ), spring precipitation (MAM; mm), and spring intensity ( $\mathrm{mm} \mathrm{day}^{-1}$ ) for observed, global CMIP5 model members, NARCCAP model members, and RCM high resolution model members.

\begin{tabular}{|c|c|c|c|c|c|c|c|}
\hline \multicolumn{8}{|l|}{ Observations } \\
\hline \multirow[t]{6}{*}{$\mathrm{CPC}$} & \multicolumn{2}{|c|}{$\begin{array}{l}\text { Annual } \\
\text { precipitation (mm) }\end{array}$} & \multicolumn{2}{|c|}{$\begin{array}{l}\text { Spring (MAM) } \\
\text { precipitation (mm) }\end{array}$} & \multicolumn{2}{|c|}{$\begin{array}{l}\text { MAM intensity, } \\
\%\left(\geq 24 \text { mm day }^{-1}\right)\end{array}$} & \\
\hline & \multicolumn{2}{|c|}{908.2} & \multicolumn{2}{|c|}{236.9} & \multicolumn{2}{|c|}{0.2} & \\
\hline & \multicolumn{6}{|c|}{ Models } & \\
\hline & \multicolumn{6}{|c|}{ Present (1980-1999) } & Future (2041-2065) \\
\hline & \multicolumn{2}{|c|}{$\begin{array}{l}\text { Annual } \\
\text { precipitation bias }\end{array}$} & \multicolumn{2}{|c|}{$\begin{array}{l}\text { MAM precipitation } \\
\text { bias }\end{array}$} & \multicolumn{2}{|c|}{ MAM intensity bias } & $\begin{array}{l}\text { MAM intensity change, } \\
\mathrm{mm} \mathrm{day}^{-1}\left(\geq 24 \mathrm{~mm} \mathrm{day}^{-1}\right)\end{array}$ \\
\hline & $\mathrm{mm}$ & $\%$ & $\mathrm{~mm}$ & $\%$ & $\begin{array}{c}\mathrm{mm} \mathrm{day}^{-1} \\
\left(\geq 24 \mathrm{~mm} \mathrm{day}^{-1}\right)\end{array}$ & $\begin{array}{c}\mathrm{mm} \mathrm{day}^{-1} \\
\left(\geq 24 \mathrm{~mm} \mathrm{day}^{-1}\right)\end{array}$ & \\
\hline \multicolumn{8}{|l|}{$\overline{C M I P 5}$} \\
\hline ACCESS1 & 372.4 & 41.0 & 102.9 & 43.5 & 1.0 & 475.0 & 0.6 \\
\hline ACCESS3 & 321.9 & 35.4 & 122.9 & 51.9 & 1.3 & 600.0 & 0.9 \\
\hline CCSM4 & 100.5 & 11.1 & 39.2 & 16.6 & 0.2 & 75.0 & 0.0 \\
\hline CESM1-CAM5 & 73.4 & 8.1 & 17.1 & 7.2 & 0.7 & 300.0 & 0.3 \\
\hline CMCC-CM & 266.3 & 29.3 & 107.3 & 45.3 & 2.6 & 1175.0 & 0.1 \\
\hline CMCC-CMS & 393.7 & 43.3 & 98.0 & 41.4 & 2.3 & 1075.0 & 2.3 \\
\hline CSIRO-Mk3-6.0 & -16.3 & -1.8 & 52.0 & 22.0 & 0.3 & 125.0 & 0.8 \\
\hline EC-Earth & 201.3 & 22.2 & 92.1 & 38.9 & 0.8 & 375.0 & 0.2 \\
\hline FGOALS-g2 & 85.7 & 9.4 & 43.1 & 18.2 & 1.3 & 600.0 & 0.2 \\
\hline HadGem2-AO & 75.0 & 8.3 & 58.5 & 24.7 & 0.9 & 436.7 & 1.2 \\
\hline MIROC5 & 131.0 & 14.4 & 4.7 & 2.0 & 0.9 & 425.0 & 0.9 \\
\hline MRI-CGCM3 & 226.9 & 25.0 & 101.2 & 42.7 & 1.6 & 725.0 & 0.4 \\
\hline \multicolumn{8}{|l|}{ NARCCAP } \\
\hline $\mathrm{CRCM}(\mathrm{ccsm})$ & -0.5 & 0.0 & 72.8 & 30.7 & 0.2 & 110.5 & 0.1 \\
\hline $\mathrm{CRCM}(\mathrm{cgcm} 3)$ & 108.6 & 12.0 & 67.1 & 28.3 & 0.3 & 125.0 & 0.4 \\
\hline $\mathrm{ECP} 2(\mathrm{gfdl})$ & 317.8 & 35.0 & 57.9 & 24.5 & 0.7 & 325.0 & 0.3 \\
\hline ECP2(hadcm3) & 108.0 & 11.9 & 12.1 & 5.1 & 0.4 & 181.1 & 0.7 \\
\hline HRM(hadcm3) & 165.2 & 18.2 & 66.8 & 28.2 & 1.4 & 666.7 & 1.8 \\
\hline MM5I $(\operatorname{ccsm})$ & 36.4 & 4.0 & 43.2 & 18.2 & 0.3 & 136.8 & 0.4 \\
\hline MM5I(hadcm3) & 55.3 & 6.1 & 53.6 & 22.6 & 1.4 & 666.7 & 0.7 \\
\hline $\mathrm{RCM} 3(\mathrm{cgcm} 3)$ & 303.1 & 33.4 & 112.4 & 47.4 & 0.6 & 275.0 & 0.2 \\
\hline RCM3(gfdl) & 252.1 & 27.8 & 73.0 & 30.8 & 0.1 & 50.0 & 1.3 \\
\hline WRF(cgcm 3$)$ & 49.5 & 5.4 & 42.6 & 18.0 & 0.3 & 150.0 & 0.7 \\
\hline \multicolumn{8}{|l|}{ RCM4(HiRes) } \\
\hline RCM4(gfdl) & -114.7 & -12.6 & -18.3 & -7.7 & 0.3 & 125.0 & 0.2 \\
\hline RCM4(hadgem) & -59.5 & -6.6 & -37.2 & -15.7 & 0.4 & 181.1 & 0.1 \\
\hline
\end{tabular}

18-41 $\mathrm{mm} \mathrm{day}^{-1}$ range as well as simulating additional, high intensity events (Figures 5(a) and (d)). For extreme intensity values in the WLEB $\left(\geq 24 \mathrm{~mm}\right.$ day $^{-1}$, informed by historically modelled streamflow data for the Maumee Basin), the relative error in historical spring (MAM) probabilities ranged from 75 to $1175 \%$ for CMIP5, 50 to $667 \%$ for NARCCAP, and 125 to $181 \%$ for RCM-HiRes (Table 2). As in the GLB region, there are several CMIP5 model members that show more intense events than the regional models in MAM and JJA (Figures 5(a) and (b)). Summer in the WLEB shows good agreement with historically observed probabilities for small to moderate events $\left(\leq 24 \mathrm{~mm} \mathrm{day}^{-1}\right)$, however the simulations include higher events that are not present in the observations (Figure 5(b)). The CMIP5 mean exceeds the historical range by eight bins, equating to almost $48 \mathrm{~mm}$ (6 $\mathrm{mm}$ per bin) or 1.9 inches (Figure 5(b)). However, the associated probabilities indicate a low frequency of these events with values close to $0.1 \%$, or 1.8 events per 20 years (Figure 5(b)).

\subsubsection{Future Precipitation Intensity (2041-2060)}

We examine the change in daily precipitation rate probabilities between the historical (1980-1999) and future (2041-2060) periods for the three ensembles (Figures 4(e)-(h) and 5(e)-(h)). We calculate the change in probability as the difference of the future probability with that of the historical probability. For example, from the $\sim 1800$ days included in MAM over 20 years, a typical extreme event may have a $1 \%$ probability. This is equivalent to about 18 events over the 20 -year period for that season. If the probability of such an extreme event increased relatively by $0.1 \%$, that would increase total MAM extreme events by 1.8 events between the 20 -year periods. For small precipitation events, the GLB ensemble means show negative changes across all seasons (1.0-3.4\% decrease in probability; Figures 4(e)-(h)). The WLEB ensemble means for small events show a similar result for the spring and winter seasons, however with a slightly smaller range (0.9-1.9\% decrease), while summer and fall have a mixed sign of change (Figures 5(e)-(h)). 
GLB daily precipitation and mid-century change
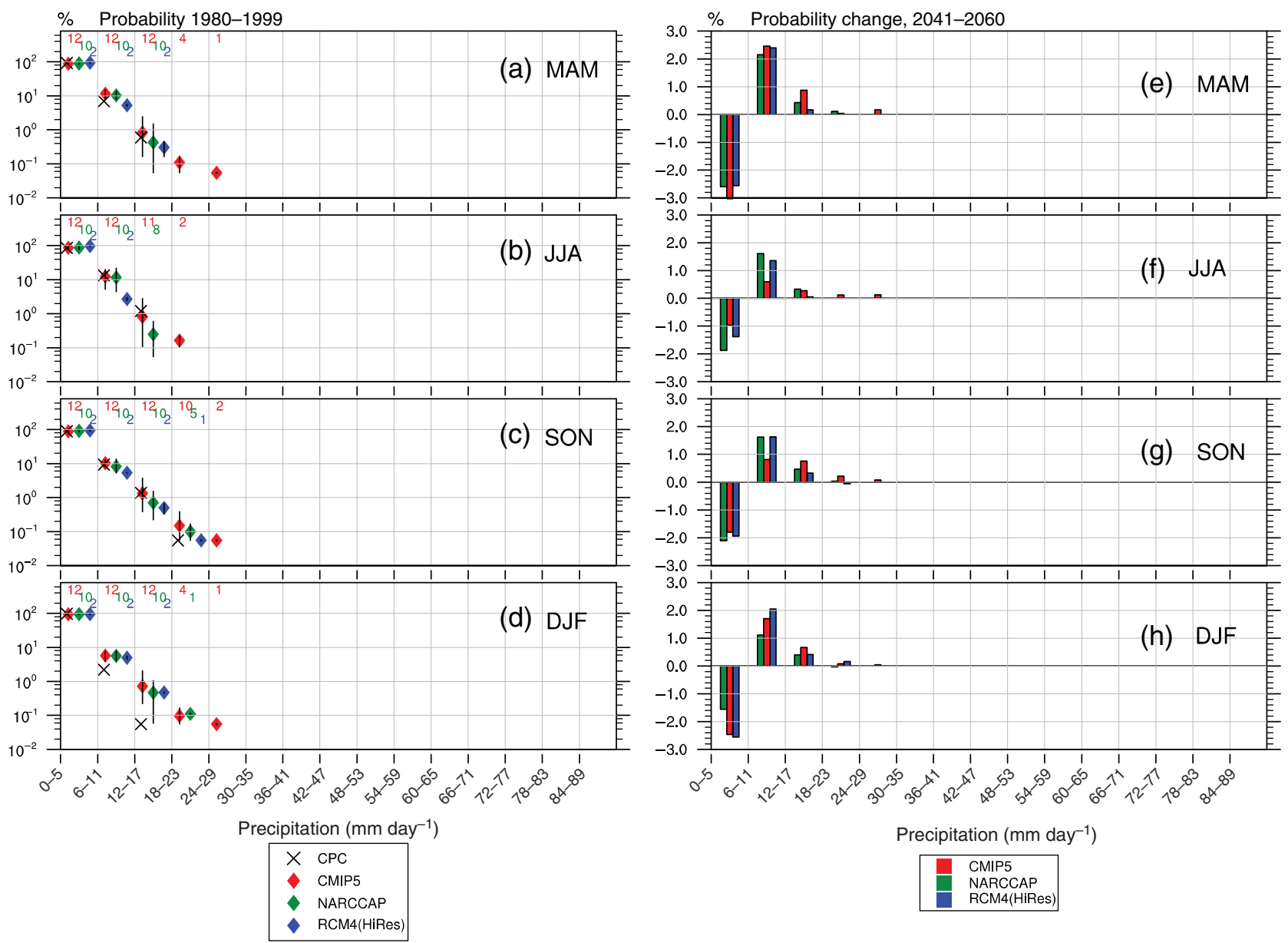

Figure 4. Historical (1980-1999) probabilities of precipitation events (binned every $6 \mathrm{~mm}^{-1 a y}{ }^{-1}$ ) spatially averaged over the GLB for (a) MAM, (b) JJA, (c) SON, and (d) DJF. Mid-century (2041-2060) projections of probability change for each bin, calculated as the difference from historical values for the GLB for (d) MAM, (e) JJA, (f) SON, and (g) DJF. Precipitation bins are averaged for each ensemble, including the CMIP5 ensemble (red), the NARCCAP ensemble (green), and the RCM-HiRes ensemble (blue). Numbers above each bin denote the total number of model members that simulated precipitation in that bin. CPC observations are denoted with a black X.

For each of the GLB ensemble means, moderate daily precipitation events across all seasons show the largest positive change (1.0-3.4\%), with extreme events showing no change (Figures $4(\mathrm{e})-(\mathrm{h})$ ). This is in part due to the spatial averaging used in this study, where averaging over a large region causes a relatively sharp drop off in the tail end of the probability distribution function (24-90 $\mathrm{mm} \mathrm{day}^{-1}$ ) for each ensemble. As compared to the GLB, the WLEB ensemble means show less consensus for the sign of moderate events, with about half of the models showing overall positive changes $(0.1-0.7 \%)$ for spring and winter extreme events. This translates to a projected increase of about 1-12 more events over the 20-year mid-century period (Figures 5(e)-(h)).

\section{Discussion}

To place these results in context, we discuss several factors related to the spatial averaging employed in this study, the climate model resolution and the model representation of physical processes such as lakes to understand model biases and projections of future precipitation in the GLB and WLEB regions.

\subsection{Spatial averaging effects}

Spatial averaging across regions effectively smooths the extreme daily events, especially for the GLB region. For example, GLB intensity values (Figures 4(a)-(d)) are lower than the WLEB (Figures 5(a)-(d)) and may under-represent the intense events in the overall GLB region, suggesting that the larger spatial extent of the GLB may reduce the calculated precipitation intensity. To understand how the spatial averaging affects the calculation of the extremes, we evaluate the maximum daily precipitation rates across each region. The maximum daily precipitation intensity is defined as the greatest intensity that occurs within any individual grid cell in the region during the selected season over all years. The probability distribution of these maxima shows the likelihood of the maximum possible precipitation that can occur within each averaging region (Figure 6 for the GLB and Figure 7 for 
WLEB daily precipitation and mid-century change

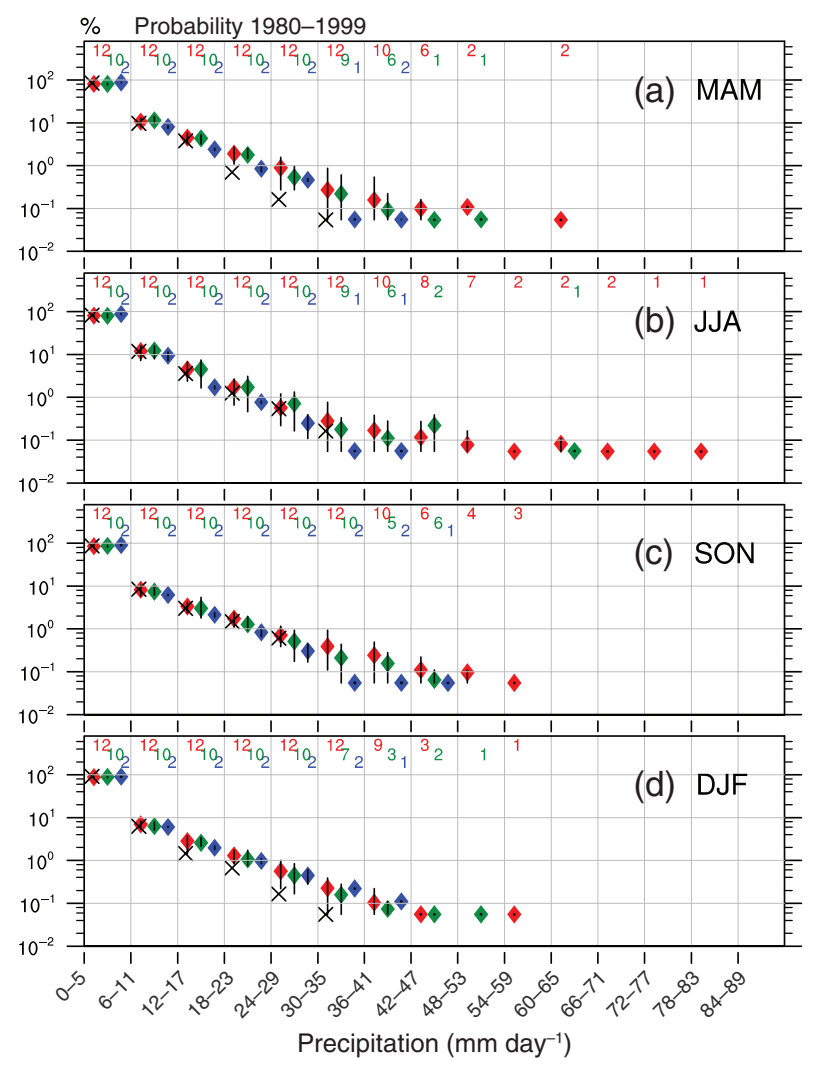

$$
\begin{array}{|ll|}
\times & \text { CPC } \\
& \text { CMIP5 } \\
\text { NARCCAP } \\
\text { RCM4(HiRes) }
\end{array}
$$

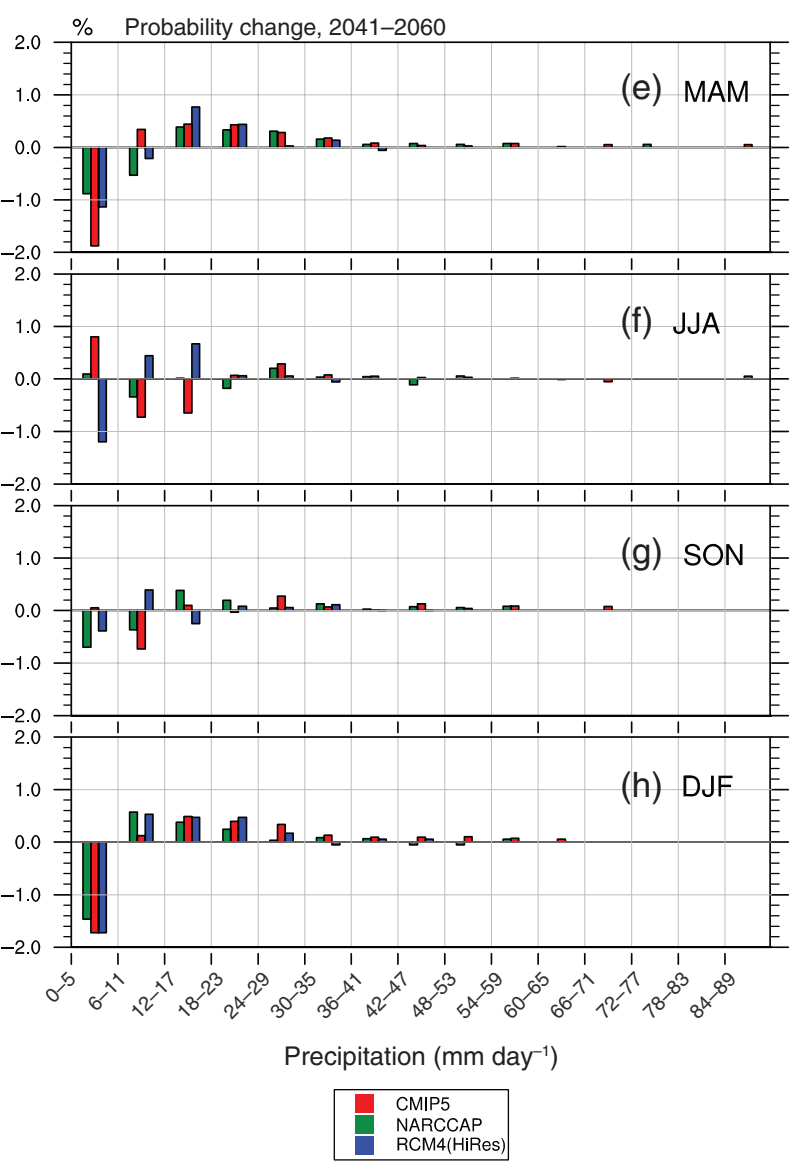

Figure 5. As for Figure 4, but for the WLEB region. the WLEB). For example, in the GLB in MAM, observations show a $0.05 \%$ probability in the $150-174 \mathrm{~mm} \mathrm{day}^{-1}$ bin, which indicates that at least one grid cell in the GLB reached a daily precipitation value in this range. This probability is equivalent to about one spring event of this intensity over the 20 -year averaging period (1980-1999). This provides a metric for the spatial distribution of precipitation intensity at any point within the region and can be useful to compare with the regional averages (Figures 4 and 5).

Over the GLB region, CMIP5 models tend to underestimate the maximum probability values (Figures 6(a)-(d)). Generally, the regional model ensembles (NARCCAP and RCM-HiRes) simulate a larger number of extreme events that more accurately captures the maximum daily precipitation distribution (Figures 6(e)-(1)). The dynamically downscaled models do tend to have some models that overestimate the maximum intensity, most notably in the spring (Figures 6(e) and (i)) and summer (Figures 6(f) and (j)). In the fall, not all NARCCAP ensemble members capture the event range and only one model (HRM3-HadCM3) extends beyond the historical CPC range (Figure 6(g)) while the HiRes members are split for larger event sizes (above $50 \mathrm{~mm} \mathrm{day}^{-1}$ ) (Figure 6(k)). In the winter, the NARCCAP ensemble shows a spread around historical probabilities (Figure 6(h)) while the
HiRes members have more occurrences of extreme events above $50 \mathrm{~mm} \mathrm{day}^{-1}$ (Figure 6(1)). In the WLEB region (Figure 7), the dynamically downscaled models also show an improvement over the global models in the simulation of intense precipitation. However, NARCCAP extends the range beyond CPC probabilities for all WLEB seasons (Figures 7(e) and (f)), while the HiRes shows a higher intensities for WLEB summer and winter (Figures 7(j) and (1)). The tendency for the NARCCAP models to produce large extremes in excess of observed values has been noted in other studies that evaluated the model performance over the entire United States (Caldwell, 2010; Kawazoe and Gutowski, 2013b; Wehner, 2013). Here, these results show that the regional models produce some grid cells with very high intensity events (e.g. $>250 \mathrm{~mm} \mathrm{day}^{-1}$ in JJA), but overall, the finer resolution models better capture the high intensity events across the two regions.

To further evaluate the effects of area averaging, we also examined the spatial distribution of the 99th percentile precipitation (considering rain days on which the precipitation was over $1 \mathrm{~mm} \mathrm{day}^{-1}$ ) in the WLEB region to determine if certain grid points have substantially higher precipitation extremes. Evaluation of seasonal averages shows no appreciable spatial pattern in seasons outside of DJF. Figure 8 shows the 99th percentile for the ten NARCCAP models 
GLB maximum daily precipitation and event probaility 1980-1999
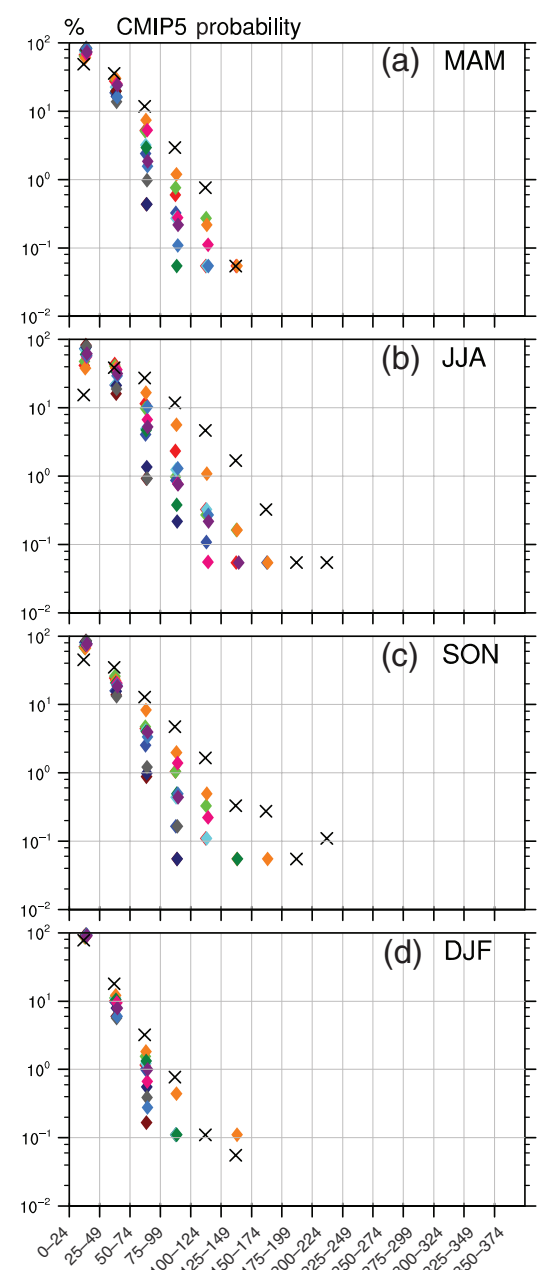

Precipitation $\left(\mathrm{mm}\right.$ day $\left.^{-1}\right)$

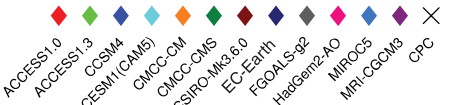

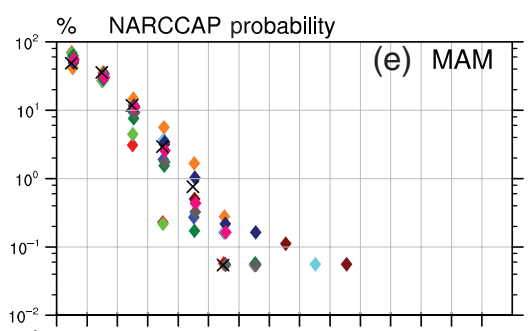
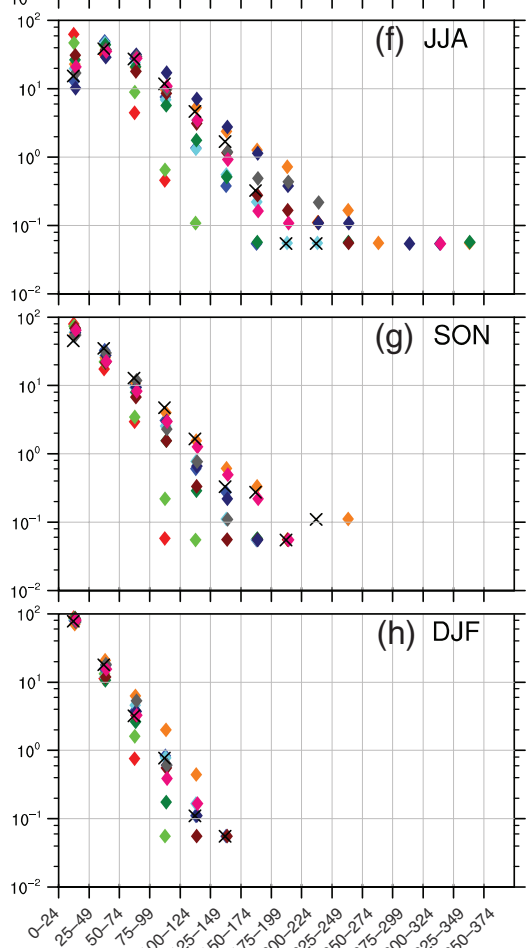

Precipitation $\left(\mathrm{mm}^{\mathrm{day}}{ }^{-1}\right)$

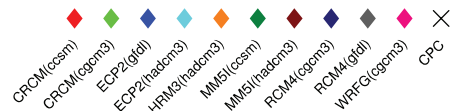

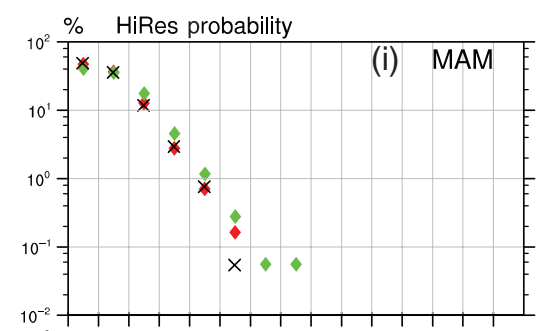
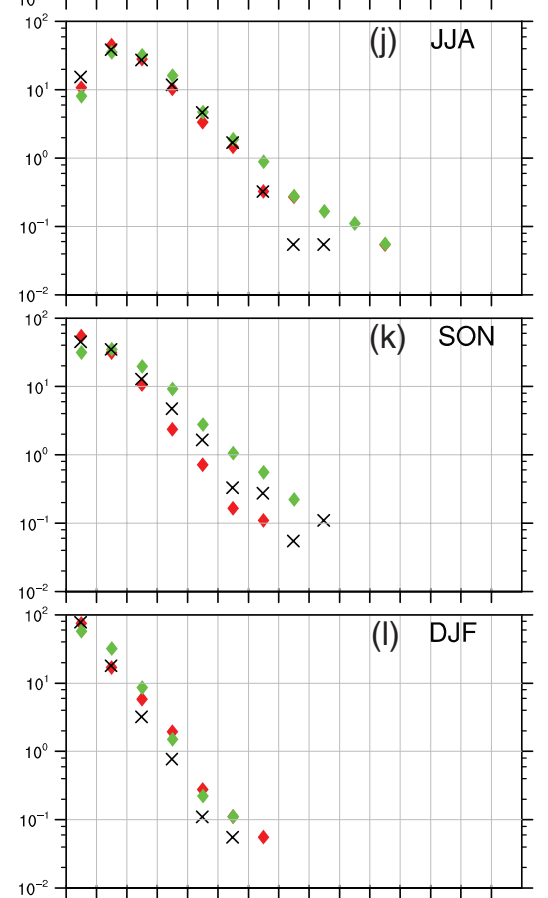

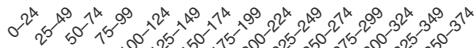

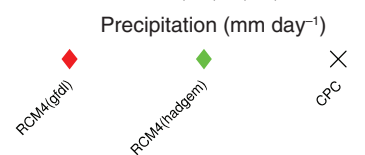

Figure 6. Maximum probabilities for each precipitation size (bins spaced every $6 \mathrm{~mm}^{-1} \mathrm{yy}^{-1}$ ) extracted from the GLB region before averaging. Ensemble probability distribution functions are shown for each season; (a-d) CMIP5, (e-h) NARCCAP, and (i-l) RCM-HiRes. CPC observations are denoted with a black $\mathrm{X}$.

and the CPC observations. In several of the NARCCAP members, and to some extent in the observations, the 99th percentile precipitation is largest near the lakes, suggesting these larger extremes are related to the production of lake effect snow in winter. For some models, the lake temperatures are interpolated from the nearest sea surface temperatures (SST). Bryan et al. (2015) showed that southern Great Lakes SSTs lake temperatures were biased warm compared to observations when using this method, enhancing precipitation near the lake in this model. Examination of the patterns of the GCMs did not reveal similar lake effects (not shown), likely because the grid spacing is too large to simulate lake-precipitation feedbacks or the lakes are absent, as discussed below.

\subsection{Resolution effects}

Another potential factor in the differences in precipitation intensity is the climate model resolution. In the
GLB region, the CMIP5 ensemble mean has higher intensities than the dynamically downscaled models (Figures 4(a)-(d)) and this effect is magnified for the WLEB (Figures 5(a)-(d)). Within the CMIP5 ensemble, the CMCC-CMS model consistently places non-zero probabilities in higher intensity bins beyond those of the historical record for both regions (individual model members not shown in Figures 4 and 5).

For the WLEB we evaluated two simulations with the $\mathrm{CMCC}$ model, the $\mathrm{CMS}$ version $\left(1.875^{\circ}\right.$ resolution, which resolves the stratosphere) and the finer CMCC-CM $\left(0.75^{\circ}\right.$ resolution, the highest resolution CMIP5 model in our ensemble). While these model versions have several parameterization differences, the increase in horizontal spatial resolution does not explain the historical bias for intense daily events. The two resolution versions show similar bias in the spring extreme event probability (1075 and $1175 \%$ respectively; Table 2). However, 
WLEB maximum daily precipitation and event probaility 1980-1999
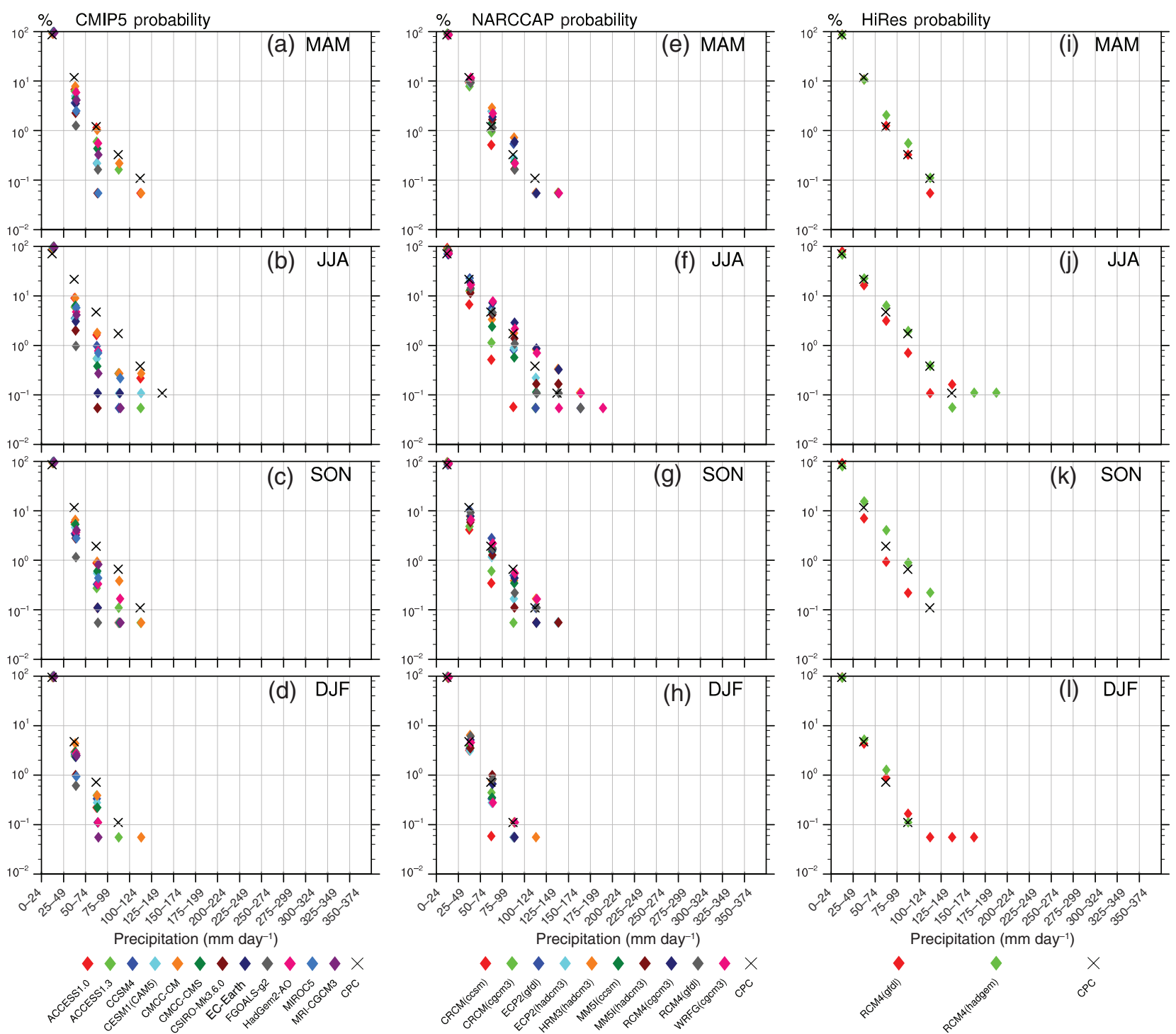

Figure 7. Maximum probabilities for each precipitation size (bins spaced every $6 \mathrm{~mm} \mathrm{day}^{-1}$ ) extracted from the WLEB region before averaging. Ensemble probability distribution functions are shown for each season; (a-d) CMIP5, (e-h) NARCCAP, and (i-l) RCM-HiRes. CPC observations are denoted with a black X.

CCSM4 and CESM1-CAM5 $\left(0.9^{\circ} \times 1.25^{\circ}\right.$ each $)$ are also relatively high resolution in our CMIP5 ensemble (187 grid cells for the WLEB), but show a larger difference in extreme event probability bias (75 and $300 \%$, respectively; Table 2). Interestingly, the CSIRO model, which has a coarser resolution equal to the CMCC-CMS model $\left(1.875^{\circ}\right)$, has less bias for extreme daily events (125 and $1075 \%$, respectively; Table 2) and also exhibits a lower bias for MAM seasonal precipitation than CMCC-CMS ( 22.0 and $41.4 \%$, respectively; Table 2 ). While it is not surprising that the models produce very different precipitation distributions due to large number of variable parameterizations in the model (e.g. convective precipitation, microphysics, and land surface), the comparison here shows that higher resolution alone within the CMIP5 ensemble does not improve the precipitation intensity bias simulated in the region. This is consistent with other studies, e.g.
Kawazoe and Gutowski (2013a) found that CMIP5 model resolution could not explain biases in precipitation intensity over the upper Mississippi region in the winter. Additionally, six global models show relatively low bias for spring precipitation (CCSM4 at $16.6 \%$, CESM1 at $7.2 \%$, CSIRO at $22.0 \%$, FGOALS at $18.2 \%$, HadGEM2 at $24.7 \%$, and MIROC at $2.0 \%$, respectively; Table 2), which is similar to several of the regional models for this metric (about 7-25\%; Table 2).

For the WLEB spring and summer seasons (Figures 5(a) and (b)), observed intensities reach up to $30-35 \mathrm{~mm} \mathrm{day}^{-1}$. However, ten of the CMIP5 models place probabilities in the next available bin (36-41 mm day ${ }^{-1}$ ) for spring, summer, and fall (nine models for winter), showing that most of the CMIP5 ensemble overemphasizes the magnitude of intense events by at least $6 \mathrm{~mm} \mathrm{day}^{-1}\left(0.2\right.$ inch day $\left.^{-1}\right)$ for these seasons. Multiple models go beyond this lower 
(a)

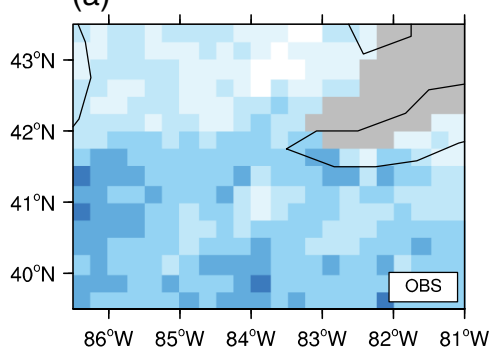

(b)

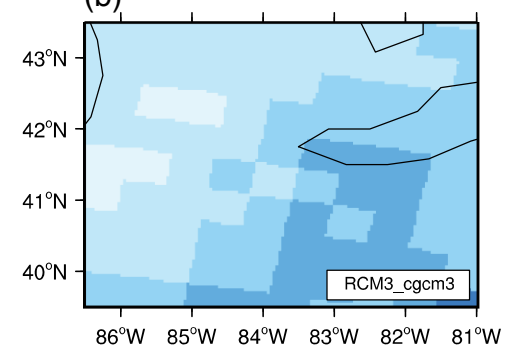

(c)

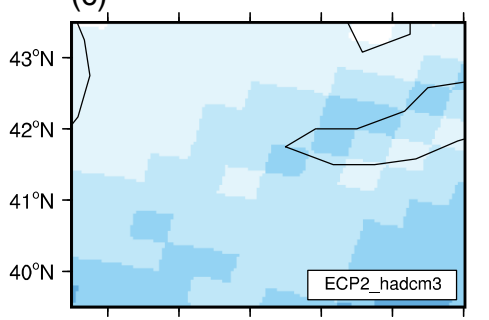

$86^{\circ} \mathrm{W} \quad 85^{\circ} \mathrm{W} \quad 84^{\circ} \mathrm{W} \quad 83^{\circ} \mathrm{W} \quad 82^{\circ} \mathrm{W} \quad 81^{\circ} \mathrm{W}$

(d)

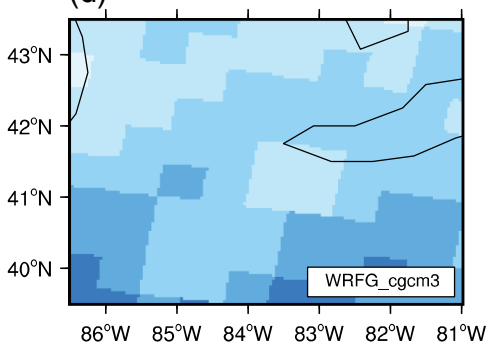

(e)

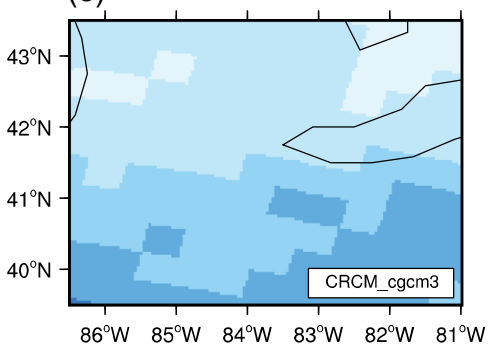

(f)

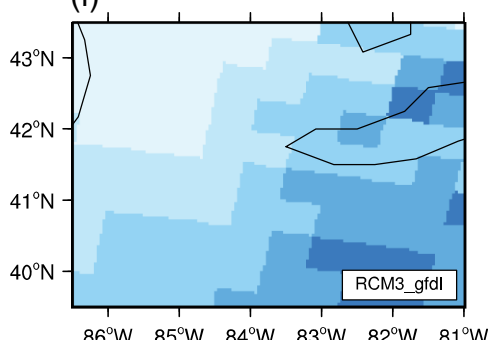

(g)

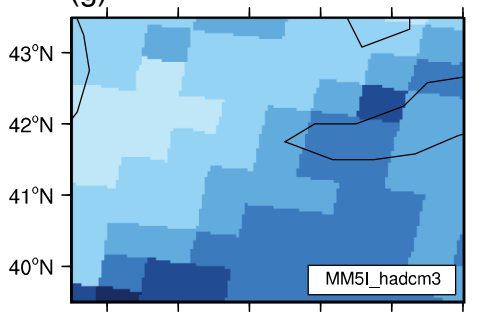

$86^{\circ} \mathrm{W} \quad 85^{\circ} \mathrm{W} \quad 84^{\circ} \mathrm{W} \quad 83^{\circ} \mathrm{W} \quad 82^{\circ} \mathrm{W} \quad 81^{\circ} \mathrm{W}$ (h)

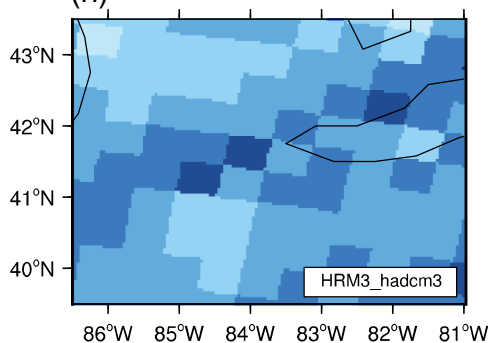

(i)

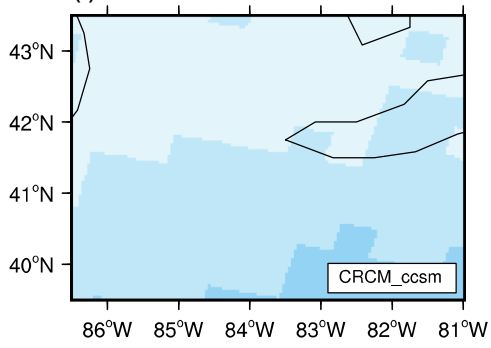

(j)

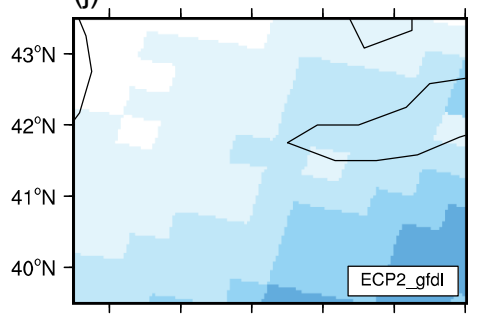

$86^{\circ} \mathrm{W} \quad 85^{\circ} \mathrm{W} \quad 84^{\circ} \mathrm{W} \quad 83^{\circ} \mathrm{W} \quad 82^{\circ} \mathrm{W} \quad 81^{\circ} \mathrm{W}$

(k)

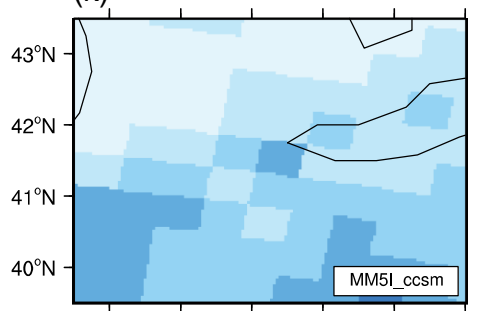

$86^{\circ} \mathrm{W} \quad 85^{\circ} \mathrm{W} \quad 84^{\circ} \mathrm{W} \quad 83^{\circ} \mathrm{W} \quad 82^{\circ} \mathrm{W} \quad 81^{\circ} \mathrm{W}$

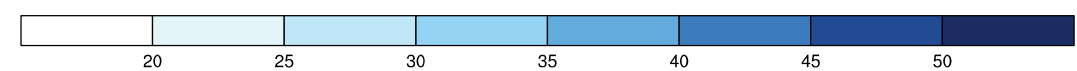

Figure 8. The 99th percentile DJF precipitation $\left(\mathrm{mm} \mathrm{day}^{-1}\right.$ ) (for days with $>1 \mathrm{~mm}^{-1}$ of precipitation) over the WLEB grid cells for (a) observations and (b-k) the NARCCAP ensemble members (Table 1), including (b) RCM3-CGCM3, (c) EPC2-HadCM3, (d) WRFG-CGCM3, (e) CRCM-CGCM3, (f) RCM3-GFDL, (g) MM5I-HadCM3, (h) HRM3-HadCM3, (i) CRCM-CCSM, (j) EPC2-GFDL, and (k) MM5I-CCSM. Darker colors indicate higher values of extreme precipitation within that grid cell. [Colour figure can be viewed at wileyonlinelibrary.com].

end bias and have non-zero probabilities in even higher bin ranges, with half of the CMIP5 ensemble represented in the $42-47 \mathrm{~mm} \mathrm{day}^{-1}$ range for spring and fall, eight models for summer and three models for winter producing a bias of at least $12 \mathrm{~mm} \mathrm{day}^{-1}\left(0.5\right.$ inch day $\left.^{-1}\right)$. Further, seven models in the CMIP5 ensemble place non-zero probabilities in the $48-53 \mathrm{~mm} \mathrm{day}^{-1}$ range giving a bias of at least $18 \mathrm{~mm} \mathrm{day}^{-1}$ for the summer period. In contrast, the regionally averaged RCM simulations overall do not exhibit such a high intensity, with lower average probabilities across all seasons in both regions. This suggests that the maximum probabilities with very high intensities (Figures 6 and 7) are likely occurring over a very small number of grid cells at different times and locations, and these grid cells do not affect the overall regional average (Figures 4 and 5). For example, HRM-HadCM (Figure $8(\mathrm{k})$ ) shows that a grid cell north of Lake Erie (1 of 56 grid cells in the WLEB region in this model, or $1.78 \%$ of the model grid cells) has the highest precipitation over the WLEB $12 \%$ of the time.

\subsection{Lake representation}

Even if topographic features such as the lakes are better resolved at higher resolution, physical parameterizations may not result in better evaluation with observations (Caldwell, 2010; Rauscher et al., 2010). The representation of lakes in the region is known to play an important role in regional precipitation (Notaro et al., 2013; Suriano 
GLB and WLEB precipitation : lakes vs. no lakes

(a) GLB precipitation : models with lakes

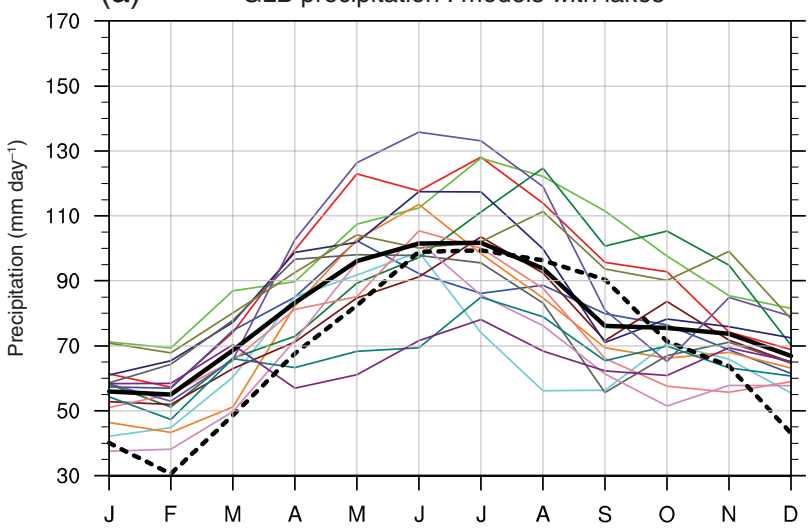

(b) WLEB precipitation : models with lakes

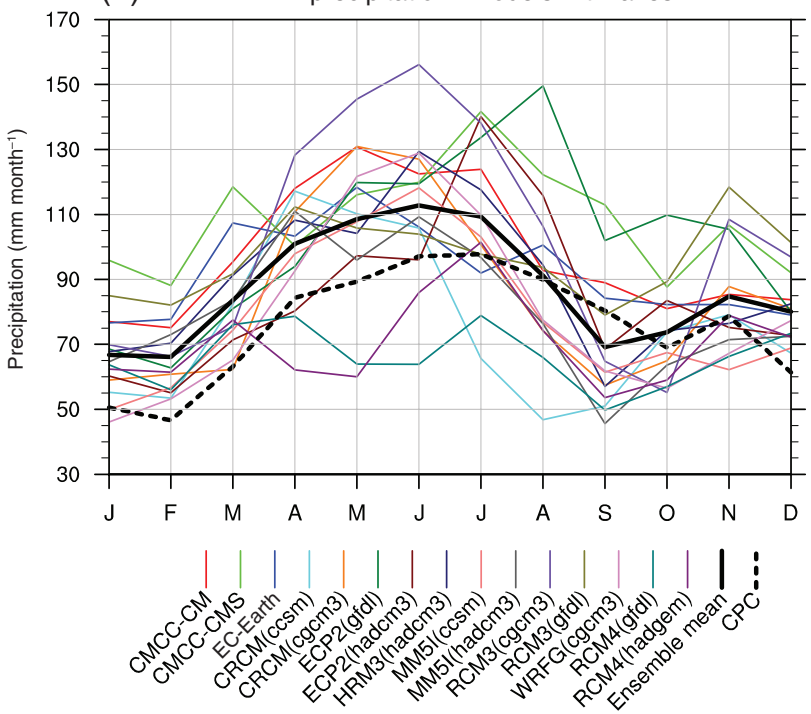

(c) GLB precipitation : models without lakes

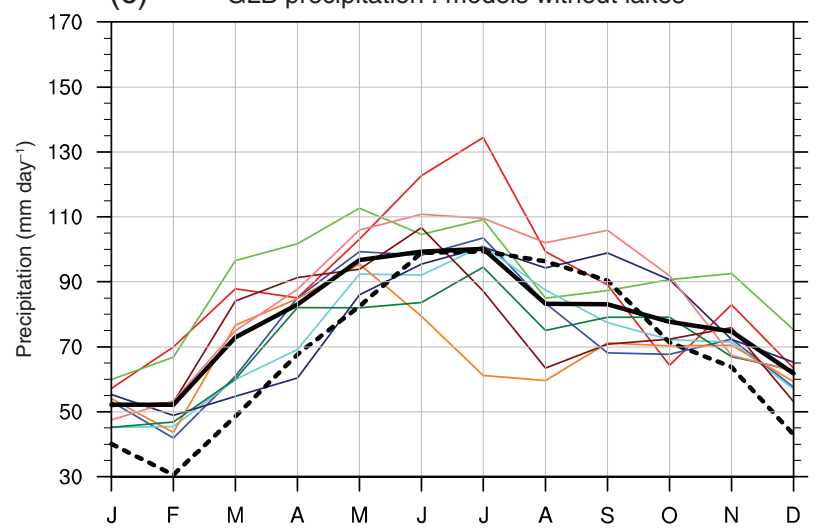

(d) WLEB precipitation : models without lakes

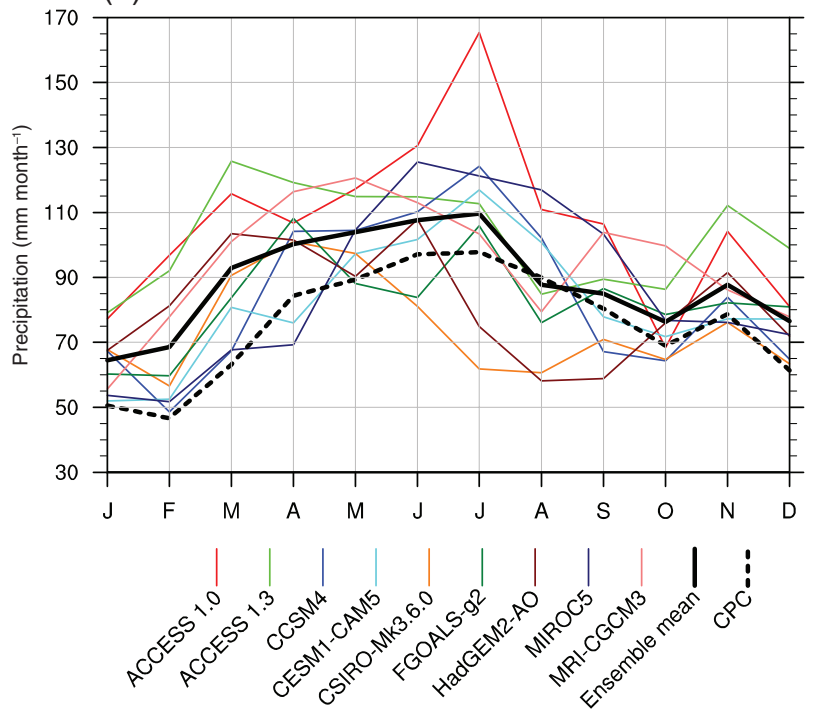

Figure 9. Monthly averages for the historical period (1980-1999) spatially averaged over the GLB and WLEB. CPC values displayed in dashed lines. (a, b) Models with lakes; including three of the CMIP5 AO models, as well as the complete NARCCAP and Hi-Res ensembles (Table 1). (c, d) Models without lakes; including eight of the CMIP5 AO models (Table 1).

and Leathers, 2016). One advantage of higher resolution models would be to include these important features at the lower model boundary condition, but resolution alone does not determine whether or not the surface is represented as bodies of water. In most of the global model members of the CMIP5 ensemble ( 9 of the 12 models), the Great Lakes are not differentiated from land (Table 1). In the NARCCAP ensemble, the lakes are represented in terms of land cover but have different treatment of lake processes that drive lake temperatures and the presence of ice. For example, most of the NARCCAP models do not use a lake model and interpolate lake surface temperatures from nearby sea surface temperatures (Table 1). As a result, there is no prognostic calculation of lake ice coverage. Three members of the NARCCAP ensemble (CRCM-CGCM3, CRCM-CCSM, and WRFG-CGCM3) simulate dynamic lake ice across the Great Lakes.

We group model members across the multiple ensembles used in this study to understand the role of lake representation in the simulation of regional precipitation.
The 15 models that represent lakes include 3 CMIP5 models (Table 1), and all 12 regional scale models (10 NARCCAP and 2 RCM HiRes). The ensemble without lakes includes the remaining nine CMIP5 models (Table 1). For the historical period, the multi-model average seasonal cycle between the models that include lakes versus those that do not is similar over the GLB (Figures 9(a) and (c)), yet there is much more variability among the members of seasonal precipitation in the lake ensemble. Both sets of models show wet biases in the winter and spring for the GLB, as well as slight dry bias in the late summer and early fall. The model bias improvement due to the lakes is inconsistent across seasons, with the spring bias slightly reduced by the models that include lakes (from a bias of 53.9 to $49.3 \mathrm{~mm}$, for models without lakes and with lakes, respectively) and the winter bias slightly increased (from 52.4 to $64.0 \mathrm{~mm}$ ).

For the WLEB, there are greater differences in monthly precipitation between the simulations with lakes (Figure 9(b)) and without lakes (Figure 9(d)). 
The summer-fall transition period shows a different response, with a small dry ASO bias for the models with lakes $(0.4 \mathrm{~mm}$ below the historical mean) while the models without lakes have a wet bias of $20.9 \mathrm{~mm}$ (Figures 9(b) and (d)), suggesting that the lake feedback during this transition period is weak. Both sets of models still overestimate winter precipitation across both regions by $54.4 \mathrm{~mm}$ for models with lakes and $51.0 \mathrm{~mm}$ for models without lakes (Figures 9(c) and (d)). This wet bias could be attributed to the lack of dynamic lake ice in many simulations, which would suppress winter precipitation (Wright et al., 2013). In addition, the lack of dynamic lake ice could also affect the projected change in precipitation, where less ice in the future may lead to greater winter precipitation.

The NARCCAP ensemble also explores the differences between local parameterizations and driving large-scale global conditions. For example, the difference in precipitation between the two similar RCM3 simulations from the NARCCAP ensemble (RCM3-CGCM3 and RCM3-GFDL, Figure 9(b)) is larger than between GCM models with lakes, with the RCM3-CGCM3 showing a large springtime precipitation bias of over $60 \mathrm{~mm}$ (Figure 9(b)). Other model pairs with different boundary conditions (e.g. ECP2-GFDL and ECP2-HadCM3; CRCM-CCSM and CRCM-CGCM3; MM5I-CCSM and MM5I-HadCM3) also show that the driving boundary conditions play an important role. In the CRCM simulations that have the most complex lake treatment, the summer drying in the WLEB is more pronounced in the CRCM-CCSM simulation $(47 \mathrm{~mm}$ in August as compared to the observed value of $90 \mathrm{~mm}$ ) than in the CRCM-CGCM3 simulation (74 mm) (Figure 9(b)). Interestingly, the other regional model driven by the CCSM (MM5I-CCSM) does not have such a strong summer dry bias and is similar to the CRCM-CGCM3 member. This suggests that while the driving global boundary conditions are important, the interactions between the regional and local processes may be the dominant driver in determining precipitation rates. Overall, this suggests that the inclusion of lakes alone does not necessarily improve model simulations of precipitation, and that the accurate representation of lake processes (e.g. Notaro et al., 2013; Mallard et al., 2015) and their interactions with large-scale dynamics are as important as including the lakes themselves.

\section{Conclusions}

We evaluate the simulation of seasonal and daily precipitation for a suite of climate models at varying resolutions for present-day and future conditions, and use resolution and configuration options to understand model biases and the range in simulated future changes in precipitation. Using seasonality as a metric, each ensemble shows positive (wet) winter and spring biases for the historical period, with greater intermodel variability in the summer and fall. At mid-century, most models show an increase in spring season precipitation of 7-18\%, in agreement with prior studies in the Midwest using the CMIP3 ensemble and other RCMs (e.g. Hayhoe et al., 2010; Vavrus and Behnke, 2014). All model ensembles including both the global CMIP5 simulations and regional simulations show a mixed signal for future summer drying. Compared to historical daily precipitation intensity, all models overestimate the observed intense precipitation events in winter and spring. Mid-century projection consensus for each region shows small increases in moderate and intense daily spring events.

This analysis highlights model biases in the region and informs the application of future climate data to specific problems. Potentially, these results highlight the need to understand the springtime bias evident in almost all of the global models and can contribute to improved representations of regional processes feedbacks and physical features. The advantage of increased resolution between the global and regional ensembles depends largely on location, boundary conditions, and physical parameterizations. For the Great Lakes region, increased resolution shows benefits in resolving daily precipitation events for the spring period as well as for the spring and summer periods in the WLEB. However for other seasons and at longer temporal averaging, boundary conditions and physical parameterizations may still play an important role in understanding and reducing the regional bias in simulated precipitation. Further analysis is needed to determine the dynamical drivers of the spring wet biases that are consistent in the global and regional models, understand how these biases affect future projections of precipitation in the region, and relay these insights to aid adaptation planning around the GLB.

\section{Acknowledgements}

This research was funded by NOAA Coastal and Oceanic Climate Applications program under grant NA13OAR4310142 and the National Science Foundation under grants 1039043 and 1600012. We thank Daniel Brown and Margaret Kalcic at the University of Michigan for helpful discussions. We also thank the North American Regional Climate Change Assessment Program (NARCCAP) for providing the data used in this research. NARCCAP is funded by the National Science Foundation (NSF), the U.S. Department of Energy (DoE), the National Oceanic and Atmospheric Administration (NOAA), and the U.S. Environmental Protection Agency Office of Research and Development (EPA). We acknowledge the World Climate Research Programme's Working Group on Coupled Modelling, which is responsible for CMIP, and we thank the climate modeling groups (listed below) for producing and making available their model output. For CMIP the U.S. Department of Energy's Program for Climate Model Diagnosis and Intercomparison provides coordinating support and led development of software infrastructure in partnership with the Global Organization for Earth System Science Portals. We thank the following individual research groups for providing their simulations to the CMIP archive: Commonwealth Scientific and 
Industrial Research Organization (CSIRO) and Bureau of Meteorology (BOM) (Australia), US National Center for Atmospheric Research (NCAR), NSF-DOE-NCAR, Centro Euro-Mediterraneo per I Cambiamenti Climatici, Queensland Climate Change Centre of Excellence and Commonwealth Scientific and Industrial Research Organisation, EC-Earth consortium, LASG (Institute of Atmospheric Physics)-CESS (Tsinghua University), National Institute of Meteorological Research/Korea Meteorological Administration, University of Tokyo, National Institute for Environmental Studies, and Japan Agency for Marine-Earth Science and Technology, and the Meteorological Research Institute.

\section{References}

Arguez A, Vose RS. 2011. The definition of the standard WMO climate normal the key to deriving alternative climate normals. Bull. Am. Meteorol. Soc. 92(6): 699-704

Bryan AM, Steiner AL, Posselt DJ. 2015. Regional modeling of surface-atmosphere interactions and their impact on Great Lakes hydroclimate. J. Geophys. Res.-Atmos. 120(3): 1044-1064.

Caldwell P. 2010. California wintertime precipitation bias in regiona and global climate models. J. Appl. Meteorol. Climatol. 49(10): 2147-2158.

Chen M, Shi W, Xie P, Silva VBS, Kousky VE, Higgins RW, Janowiak JE. 2008. Assessing objective techniques for gauge-based analyses of global daily precipitation. J. Geophys. Res.-Atmos. 113: D04110. https://doi.org/10.1029/2007JD009132.

Cherkauer KA, Sinha T. 2010. Hydrologic impacts of projected future climate change in the Lake Michigan region. J. Great Lakes Res. 36 $33-50$.

d'Orgeville M, Peltier WR, Erler AR, Gula J. 2014. Climate change impacts on Great Lakes Basin precipitation extremes. J. Geophys. Res.-Atmos. 119(18): 10799-10812.

Flato G, Marotzke J, Abiodun B, Braconnot P, Chou SC, Collins W, Cox P, Driouech F, Emori S, Eyring V, Forest C, Gleckler P, Guilyardi E, Jakob C, Kattsov V, Reason C, Rummukainen M. 2013. Evaluation of climate models. In Climate Change 2013: The Physical Science Basis. Contribution of Working Group I to the Fifth Assessment Report of the Intergovernmental Panel on Climate Change, Stocker TF, Qin D Plattner GK, Tignor M, Allen SK, Boschung J, Nauels A, Xia Y, Bex V, Midgley PM (eds). Cambridge University Press: Cambridge, UK and New York, NY.

Giorgi F, Coppola E, Solmon F, Mariotti L, Sylla MB, Bi X, Elguind N, Diro GT, Nair V, Giuliani G, Turuncoglu UU, Cozzini S, Güttler I, O'Brien TA, Tawfik AB, Shalaby A, Zakey AS, Steiner AL, Stordal F, Sloan LC, Brankovic C. 2012. RegCM4: model description and preliminary tests over multiple CORDEX domains. Clim. Res. 52(1): 7-29.

Goyette S, McFarlane NA, Flato G. 2000. Application of the Canadian Regional Climate Model to the Laurentian Great Lakes regions. Implementation of a lake model. Atmos. Ocean 38(3): 481-503.

Gronewold AD, Stow CA. 2014. Water loss from the Great Lakes. Science 343(6175): 1084-1085.

Gronewold AD, Fortin V, Lofgren B, Clites A, Stow CA, Quinn F. 2013 Coasts, water levels, and climate change: a Great Lakes perspective. Clim. Change 120(4): 697-711.

Gula J, Peltier WR. 2012. Dynamical downscaling over the Great Lakes Basin of North America using the WRF regional climate model: the impact of the Great Lakes system on regional greenhouse warming. $J$. Clim. 25(21): 7723-7742.

Gutierrez JM, San-Martin D, Brands S, Manzanas R, Herrera S. 2013. Reassessing statistical downscaling techniques for their robust application under climate change conditions. J. Clim. 26(1): 171-188.

Hayhoe K, VanDorn J, Croley T II, Schlegal N, Wuebbles D. 2010 Regional climate change projections for Chicago and the US Great Lakes. J. Great Lakes Res. 36: 7-21.

Karl TR, Melillo JT, Peterson TC. 2009. Global climate change impacts in the United States. Karl TR, Melillo JT, Peterson TC (eds). Cambridge University Press, $189 \mathrm{pp}$.

Kawazoe S, Gutowski WJ Jr. 2013a. Regional, very heavy daily precipitation in CMIP5 simulations. J. Hydrometeorol. 14(4): 1228-1242.
Kawazoe S, Gutowski WJ Jr. 2013b. Regional, very heavy daily precipitation in NARCCAP simulations. J. Hydrometeorol. 14(4): $1212-1227$

Khaliq MN, Sushama L, Monette A, Wheater H. 2015. Seasonal and extreme precipitation characteristics for the watersheds of the Canadian Prairie Provinces as simulated by the NARCCAP multi-RCM ensemble. Clim. Dyn. 44(1-2): 255-277.

Legates DR, Willmott CJ. 1990. Mean seasonal and spatial variability in gauge-corrected, global precipitation. Int. J. Climatol. 10(2): $111-127$.

Mallard MS, Nolte CG, Bullock OR, Spero TL, Gula J. 2014. Using a coupled lake model with WRF for dynamical downscaling. J. Geophys. Res.-Atmos. 119(12): 7193-7208.

Mallard MS, Nolte CG, Spero TL, Bullock OR, Alapaty K, Herwehe JA, Gula J, Bowden JH. 2015. Technical challenges and solutions in representing lakes when using WRF in downscaling applications. Geosci. Model Dev. 8: 1085-1096.

Mearns LO, Sain S, Leung LR, Bukovsky MS, McGinnis S, Biner S, Caya D, Arritt RW, Gutowski W, Takle E, Snyder M, Jones RG, Nunes AMB, Tucker S, Herzmann D, McDaniel L, Sloan L. 2013. Climate change projections of the North American Regional Climate Change Assessment Program (NARCCAP). Clim. Change 120(4): 965-975.

Meehl GA, Covey C, Delworth T, Latif M, McAvaney B, Mitchell JFB, Stouffer RJ, Taylor KE. 2007. The WCRP CMIP3 multimodel dataset - a new era in climate change research. Bull. Am. Meteorol. Soc. 88(9): 1383-1394.

Melillo JM, Richmond TC, Yohe GW (Eds). 2014. Climate change impacts in the United States: The Third National Climate Assessment. U.S. Global Change Research Program, 841 pp. https://doi.org/10.7930/J0Z31WJ2.

Michalak AM, Anderson EJ, Beletsky D, Boland S, Bosch NS, Bridgeman TB, Chaffin JD, Cho K, Confesor R, Daloglu I, DePinto JV, Evans MA, Fahnenstiel GL, He L, Ho JC, Jenkins L, Johengen TH, Kuo KC, LaPorte E, Liu X, McWilliams MR, Moore MR, Posselt DJ, Richards RP, Scavia D, Steiner AL, Verhamme E, Wright DM, Zagorski MA. 2013. Record-setting algal bloom in Lake Erie caused by agricultural and meteorological trends consistent with expected future conditions. Proc. Natl. Acad. Sci. USA 110(16): 6448-6452.

Mishra V, Cherkauer KA. 2011. Influence of cold season climate variability on lakes and wetlands in the Great Lakes region. J. Geophys. Res.-Atmos. 116: D12111. https://doi.org/10.1029/2010JD015063.

Notaro M, Bennington V, Lofgren B. 2015. Dynamical downscalingbased projections of Great Lakes water levels. J. Clim. 28(24): 9721-9745.

Notaro M, Zarrin A, Vavrus S, Bennington V. 2013. Simulation of heavy lake-effect snowstorms across the Great Lakes Basin by RegCM4: synoptic climatology and variability. Mon. Weather Rev. 141(6): 1990-2014.

Patz JA, Vavrus SJ, Uejio CK, McLellan SL. 2008. Climate change and waterborne disease risk in the Great Lakes region of the US. Am. J. Prev. Med. 35(5): 451-458.

Peters GP, Andrew RM, Boden T, Canadell JG, Ciais P, Le Quere C, Marland G, Raupach MR, Wilson C. 2013. Commentary: the challenge to keep global warming below 2 degrees C. Nat. Clim. Change 3(1): 4-6.

Rauscher SA, Coppola E, Piani C, Giorgi F. 2010. Resolution effects on regional climate model simulations of seasonal precipitation over Europe. Clim. Dyn. 35(4): 685-711.

Suriano ZJ, Leathers DJ. 2016. Twenty-first century snowfall projections within the eastern Great Lakes region: detecting the presence of a lake-induced snowfall signal in GCMs. Int. J. Climatol. 36(5): 2200-2209.

Taylor KE, Stouffer RJ, Meehl GA. 2012. An overview of CMIP5 and the experiment design. Bull. Am. Meteorol. Soc. 93(4): 485-498.

Vavrus SJ, Behnke RJ. 2014. A comparison of projected future precipitation in Wisconsin using global and downscaled climate model simulations: implications for public health. Int. J. Climatol. 34(10): 3106-3124

Wehner MF. 2013. Very extreme seasonal precipitation in the NARCCAP ensemble: model performance and projections. Clim. Dyn. 40(1-2): 59-80.

Wilby RL, Wigley TML, Conway D, Jones PD, Hewitson BC, Main J, Wilks DS. 1998. Statistical downscaling of general circulation model output: a comparison of methods. Water Resour. Res. 34(11): 2995-3008.

Wright DM, Posselt DJ, Steiner AL. 2013. Sensitivity of lake-effect snowfall to lake ice cover and temperature in the Great Lakes region. Mon. Weather Rev. 141(2): 670-689. 